\title{
Research Paper \\ Analysis of Sustainability Strategies of Range From Organizational View for Sustainable De- velopment (Case Study: South Khorasan Province)
}

\author{
*Mahmoud Fall Solayman ${ }^{1}$, Hojat Allah Sadeghi², Mohammad Haseli ${ }^{3}$, Fatemeh Amiri ${ }^{4}$
}

1. Associate Professor, Department of Geography, Faculty of Literature and Humanities, Birjand University, Birjand, Iran.

2. PhD Candidate, Young Researchers and Elite Club, Faculty of Literature and Humanities, Izeh Branch, Islamic Azad University, Izeh, Iran.

3. PhD Candidate, Department of Geography, Faculty of Geographical Sciences, Kharazmi University, Tehran, Iran.

4. MSc. Student, Department of Geography and Rural Planning, Faculty of Geographical Sciences, Kharazmi University, Tehran, Iran.

Received: 08 May. 2016 Accepted: 11 Dec. 2016

Key words:

Opportunities, Limitations, Strength, Weakness, Ranges, South khorasan, SWOT
Ctration: Fall Solayman, M., Sadeghi, H. A., Haseli, M., \& Amiri, F. (2017). [Analysis of Sustainability Strategies of Range From Organizational View for Sustainable Development (Case Study: South Khorasan Province) (Persian)]. Journal of Rural Research, 8(1), 38-53. http://dx.doi.org/10.21859/jjr-08013

http://dx.doi.org/10.21859/jjr-08013

\begin{abstract}
A BSTRACT
The current paper aimed at assessing the capacities and limitations of the model ranges in South Khorasan province (SWOT) that consisted of four components of strengths, weaknesses, opportunities and threats. Method study is based on objective, applied based on the nature and methods of descriptive analytic. That's rangelands components associated with these concepts were determined. Fifty experts in organizations and research centers associated with different areas of expertise. A weighted ranking based on SWOT, evaluated the importance of these factors to determine the positive and negative points rangelands were identified. The results showed that the potential for development and solve the problems of South Khorasan rangeland is somewhat provided. Based on the most important factor of strengths, doing point operations ranges with value 0.548 . The most important strength, the factor of type dominant livestock and Surplus depends to range with value of 0.384 . Most important opportunity to have traditional and indigenous knowledge to restoring ranges with value 0.388 and Most important threat is the lack of precipitation and the continuing drought and loss of valuable rangeland production potential with value 0.4 . Offensive strategy was determined as the best strategy for the management and development of ranges.
\end{abstract}

\section{Extended Abstract}

\section{Introduction}

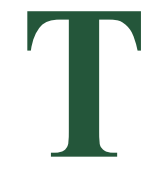

he importance of environmental issues and particularly pastures is no secret. Therefore, these areas require integrated planning and management to achieve this important first step, actual knowledge of the regional ecosystem. In other words, you must first present status and be recognized. It is better to limitations and capacities in the field of sustainable develop- ment to be known as pastures, because if true understanding, one can better plan the development of the economic and environmental areas, so as to not put pressure ranges and are not destroyed. Therefore, understanding the capabilities and limitations of pastures at the regional level is a necessity. Today, feasibility and cognitive capacities and environmental and economic constraints using analytical models have been widely popular. The purpose of this paper is to capacities and limitations of the model ranges in South Khorasan province (SWOT) consists of four components, strengths, weaknesses, opportunities and threats are analyzed. 


\section{Methodology}

Method study is based on objective, applied based on the nature and methods of descriptive-analytic. That's rangelands components associated with these concepts were determined. Using the 50 expert in Organizations and research centers associated with different areas of expertise. and a weighted ranking based on SWOT, the importance of these factors to determine the positive and negative points rangelands were identified.

\section{Results}

Among the positive factors, the most important factor was at a level equivalent to $80 \%$ of the pastures point operations with a value of 0.548 . The extent of rangeland in the final with a score of 0.484 in the second importance. As well as among the factors strengths and enable review of management plans in the most trivial known indicator is stagnant at 0.114 . Among the factors weakening the disadvantage, OS the dominant livestock in pastures (goat) and pasture-based livestock surplus value was 0.384 . In the second place, the weakness in pastures, major ecological constraints such as drought, lack of precipitation and is with a score of 0.32 .

The most trivial weakness that can be less focus on it, blurring the suitability of the province is 0.075 . Among the factors most important opportunity, indigenous and traditional knowledge in the use of surface runoff 0.388 and least important to presuppose the existence of research centers and universities in the province of applied research is at 0.072. Among the threats, the most important threat to the lack of precipitation and continuing drought and loss of livestock grazing and rangeland production potential value in excess of 0.4 , in three operating systems (traditional, butterfly grazing and range management plan implemented) with a value of 0.364 and least important threat, judicial authorities lack the necessary support in dealing with abusers natural resources is 0.079 .

Based on the analysis made of the strategies presented in 20 cases was included in the first priority of the strategy to invest in plants due to the richness of species of plants and medicinal, which is based on the matrix QSPM top score 14:34 into gained. The use of traditional and indigenous knowledge on management of surface runoff in the restoration of pastures with a score of 14.21, despite the necessary facilities and conditions, including solar, investment in plant with a score of 14.01 and a low-interest bank loan growth and appropriate rewards with a score of 13.83 in the next rankings are priorities.

\section{Discussion}

Due to internal and external factors, including opportunities, threats, strengths and weaknesses in the pastures of South Khorasan province were identified and evaluated. It can be concluded strength of existing opportunities can be effective to address known weaknesses and threats; Because study area has various opportunities including academic and research centers in the field of applied research, indigenous and traditional knowledge in the use of surface runoff to presuppose the possibility of investing part of medicinal plants, it is possible to improve gas supply clean fuels and the development of rural areas and low-interest bank credits to the business side of pastures for livestock farmers, which in turn is resulting in decreased pressure, As well as the strengths of the operations audit at a level equivalent to $80 \%$ of the pastures, pastures, rangeland large extent, the presence of native plant species resistant to environmental stress, high species richness of plants and industrial and the possibility of multi-purpose use pastures are important core features that should be considered. In fact, using the opportunities and strengths, reduce weaknesses and threats should be brought to the lowest level.

What is important in the study area, the economic and environmental problems are the most important factors that affect their pastures. In other words the one hand, environmental issues such as drought, storms and sand dunes ... and on the other hand, human performance, such as interference too much for fuel, overgrazing and lack of proper planning in the fields, meadows area will advance to a more difficult situation. Planners must therefore be considered appropriate strategy that looks at all the situations the best option is offensive strategy. In this strategy, using the strengths, determine opportunities for efficiency and promotion of the system (pasture) is used. That is complementary strengths and opportunities for improvement in pasture conditions are considered.

\section{Conclusion}

Based on the results, the strengths and opportunities of the region can affect the sustainability of rangelands and eliminate the threats and weaknesses. What should be at the helm of matters is a unified view to manage and control various factors. Choosing the optimal strategy in this field is very important. In this research, an aggressive strategy was determined to improve ranges by using the strength points and designated opportunities. The region due to the nature of governing has different environments and faces various threats such as lack of water resources and drought that planners should place these two factors 
on top of their issues to manage rangelands. The results indicate that some solutions must be considered, including encouraging the cultivation of medicinal and industrial plants (change livelihood), providing financial facilities for people to produce and create jobs and subsequently non-economic independence of rangelands, using solar and wind power to reduce pressure on rangelands fuel resources, and using resourceful indigenous knowledge to tackle environmental problems. These are some exemplary solutions that can affect the sustainable rangeland management in the region.

\section{Acknowledgments}

This research did not receive any specific grant from funding agencies in the public, commercial, or not-forprofit sectors.

\section{Conflict of Interest}

The authors declared no conflicts of interest. 


\title{
تحليل راهبردهاى يايدارى مرتع از نكاه سازمانى در راستاى توسعه يايدار روستايى (نمونه مطالعه:

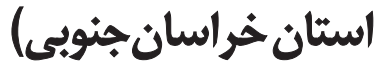

\author{
"محمود فالسليمان'، حجت الله صادقى '؛ محمد حاصلى"، فاطمه اميرى" \\ 1 - دانشيار، كروه جغرافيا، دانشكده ادبيات و علوم|نسانى، دانشُّاه بيرجند، بيرجنده ايران.

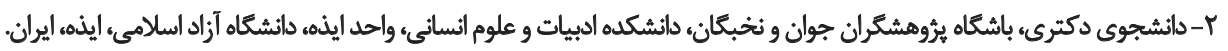

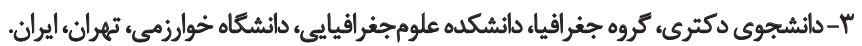

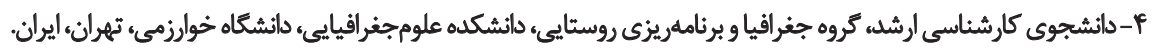

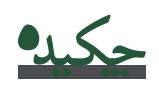

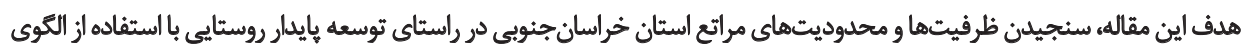

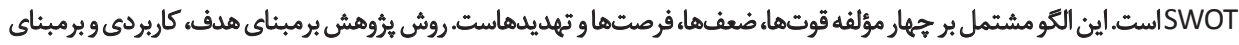

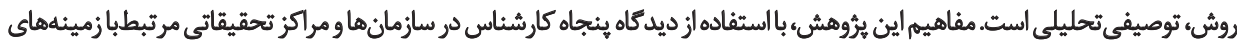

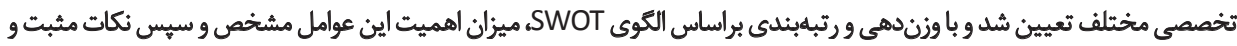

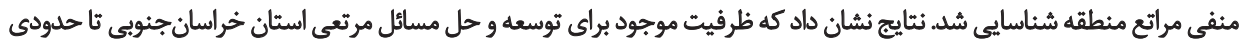

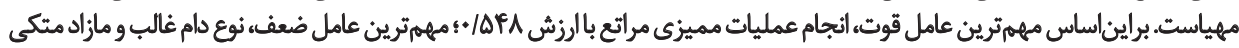

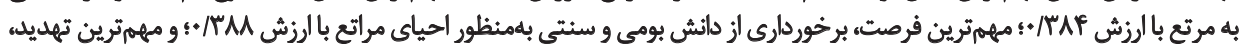

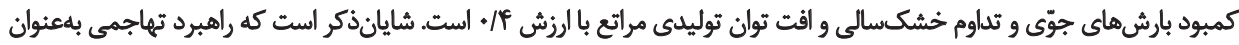

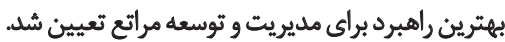

تاريخ دريافت: 19 الرديبيشت هوش

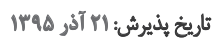

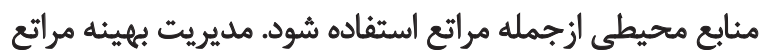
مقدمه

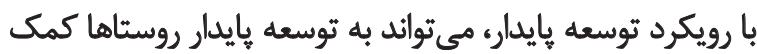

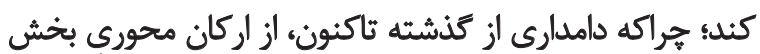

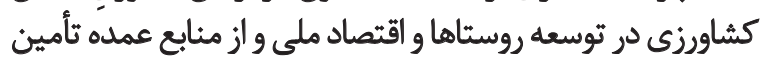

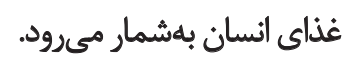

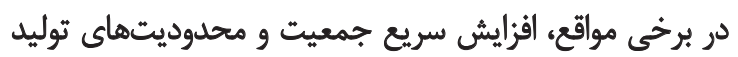

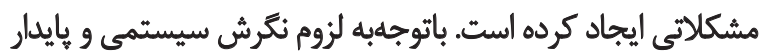

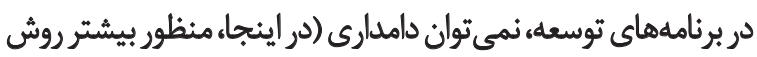

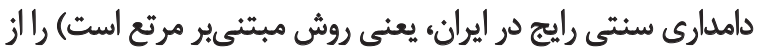

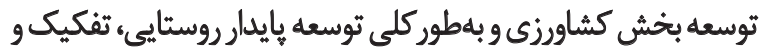

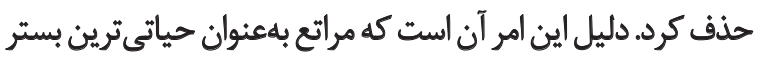

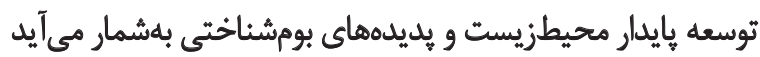

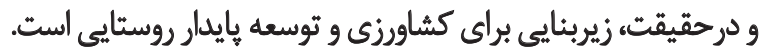

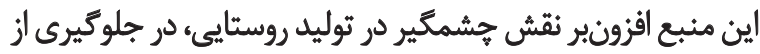

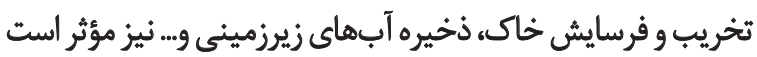

در مقوله توسعه و بايدارى محيطى، مديريت و برنامهريزى مدري

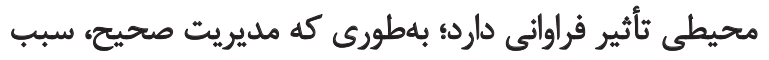

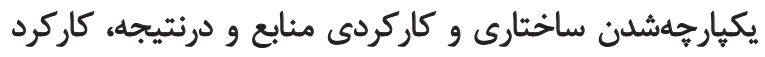

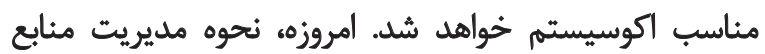

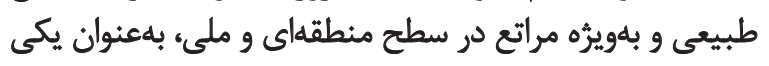

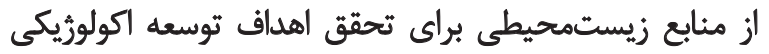

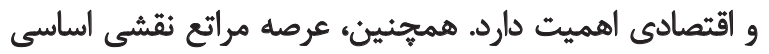

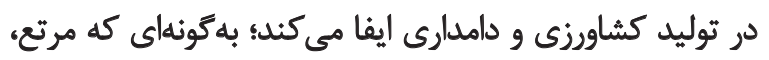

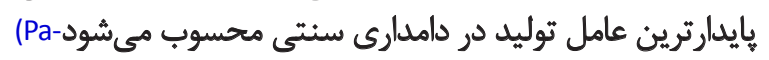

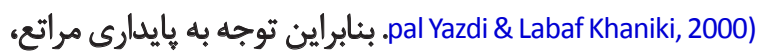

$$
\text { از نكات بارز محيطى از بُعد مديريتى است. }
$$

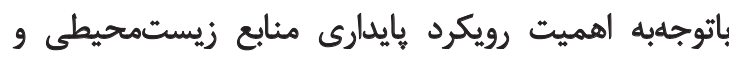

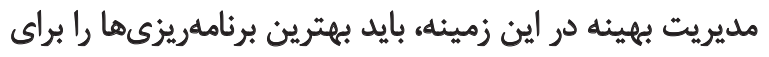

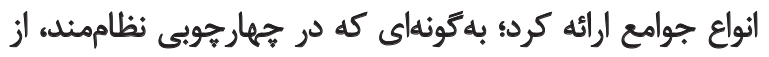




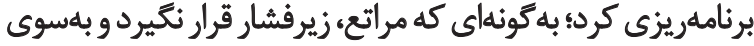

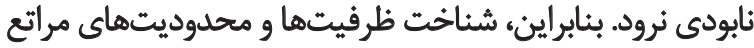
در سطح منطقهاى، موضوعى ضرورى است.

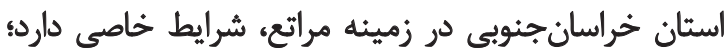

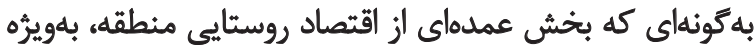

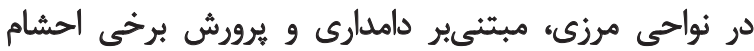

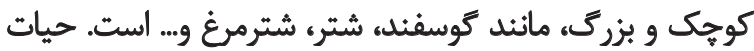

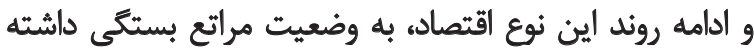

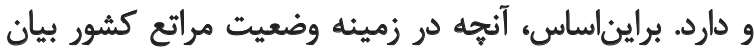

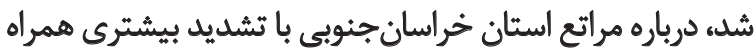

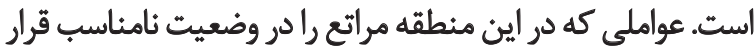

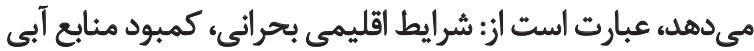

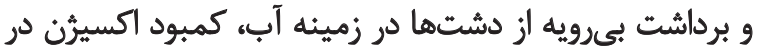

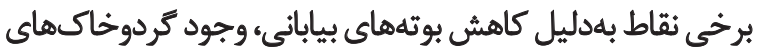

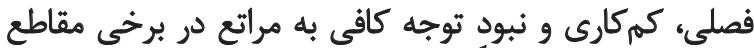

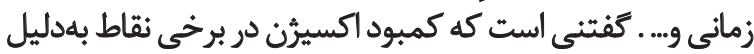

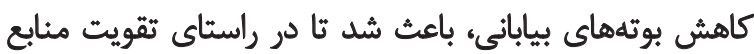

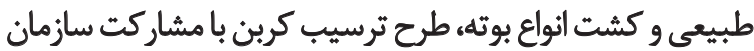
ملل در اين منطقه انجام شود. بايدارى روستاها در اين منطقه و نواحى مرزى در زمينه مينه

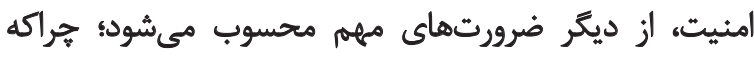

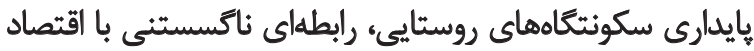

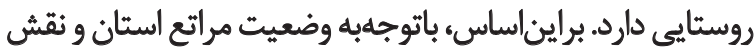

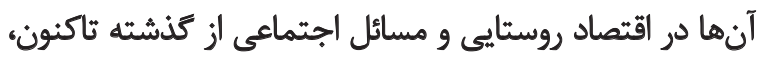

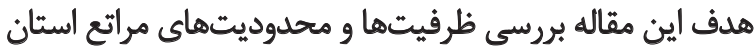

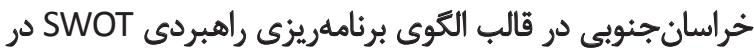

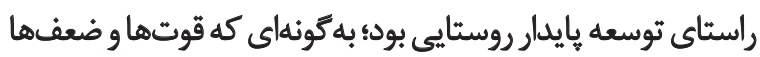
(عوامل درونى) و فرصتها و تهديدهاي سيستم (عوامل بيرونى)

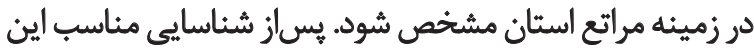

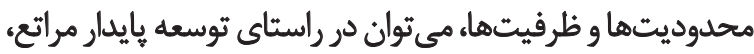

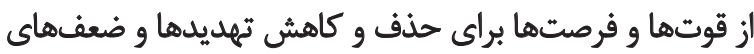

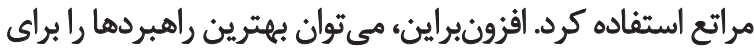

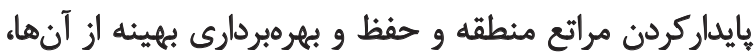

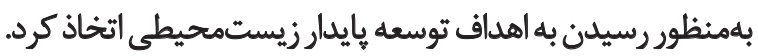

\section{مرورى بر ادبيات موضوع}

$$
\text { رويكرد مناسب محيط كرايي }
$$

هماكنون، بيش از سه دهه از توجه جهانى به موضوع حفاظت

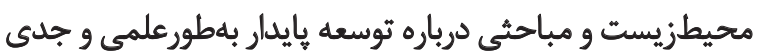

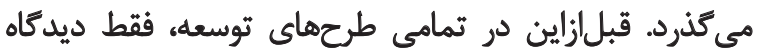

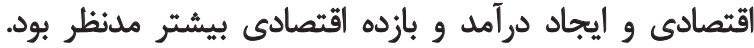

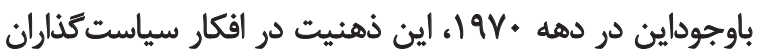

درحال حاضر، موضوع مهم در بهرهبردارى از هراتع در تغذيه

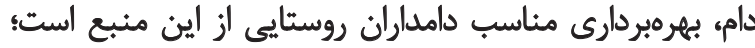

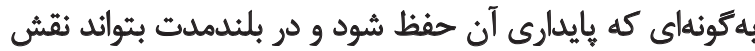

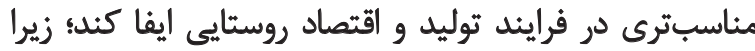

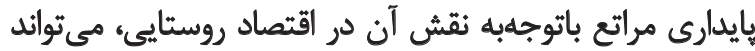

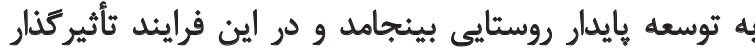

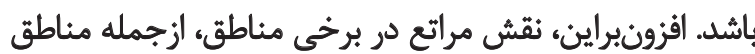

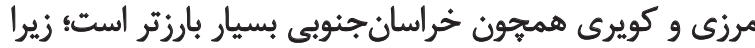

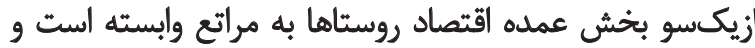

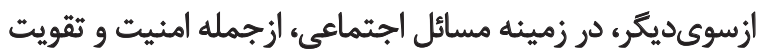

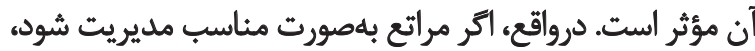

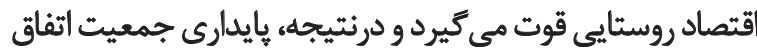

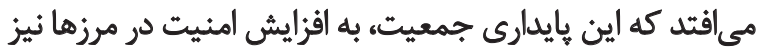

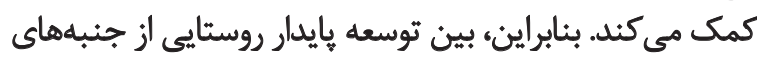

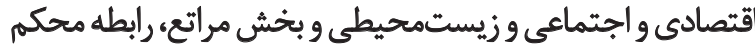

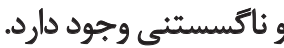

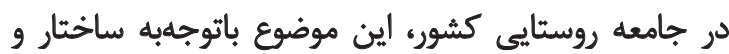

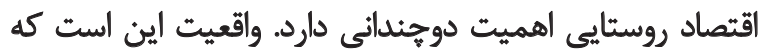

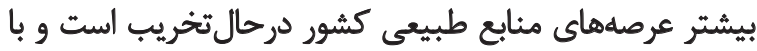

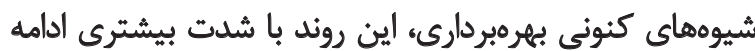

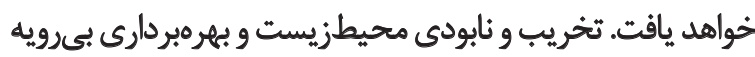

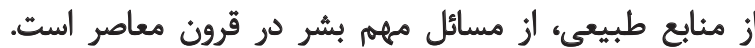

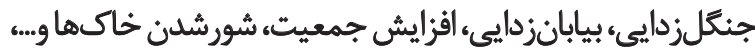

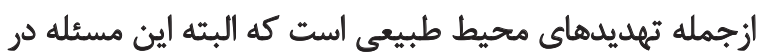
مناطق خشك و نيمه خشك شدت بيشترى دارد (Archer, 1990). بررسى منابع و مطالعات نشان مىدهد كه وضعيت كتمى دئ

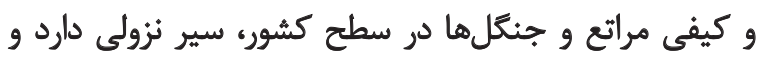

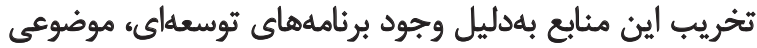

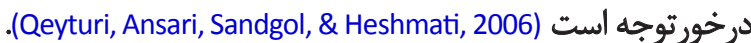
اين تخريبها متأثر از تبديل و تغيير كاربرىهاي طبيعى به

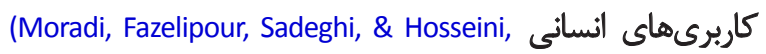
(2008، تأثيرات اقليمى در تشديد تخريب منابع طبيعى - Akbar )

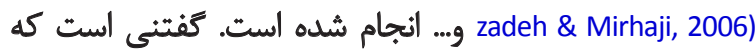

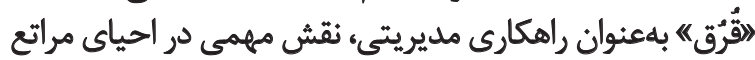
تخريبشده داشته است (Kraaij \& Milton, 2006).

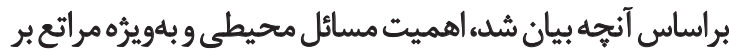

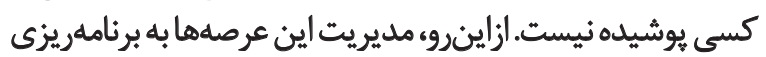

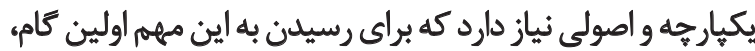

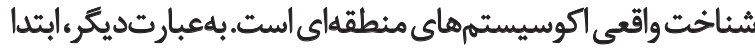

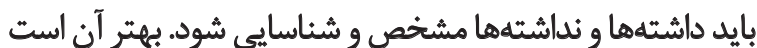

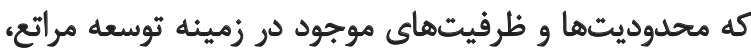

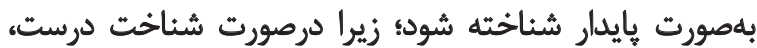

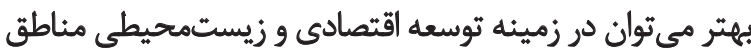


دهيم تا درنهايت به مديريت قوى محلي و توانمندسازي منتّهى شود (Kakumba, 2010).

برايناساس، بخش مراتع و توسعه بايدار آن ازجمله مسائل

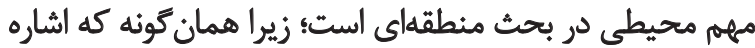

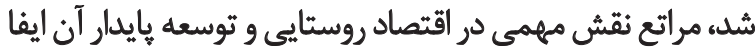

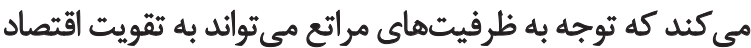

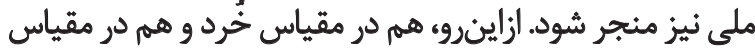

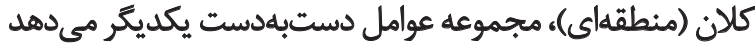

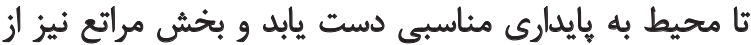

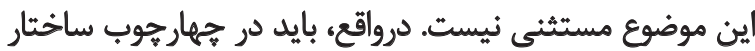

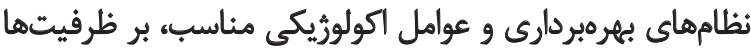
و محدوديتهاى مراتع تأكيد شود (Saeedi Garaghani, Heidari,

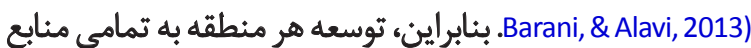

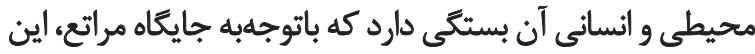
منبع در بحث ظرفيتها و محدوديتهاي منطقه مهانم است.

$$
\text { وضعيت والهميت مرانع }
$$

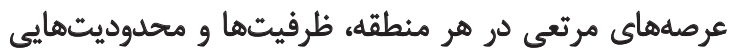

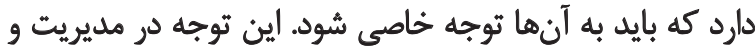

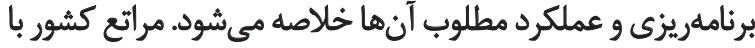

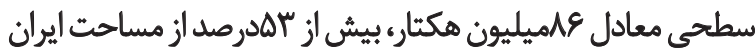
را دربرمى كيرد (Eskandari, Alizadeh, \& Mahdavi, 2008). نقش إئش

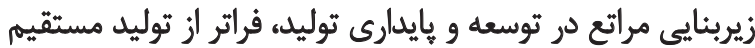

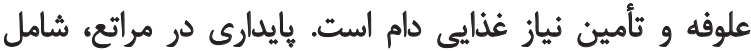

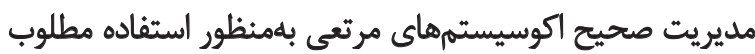

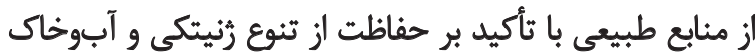

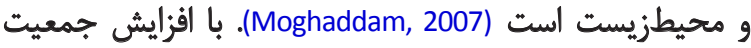

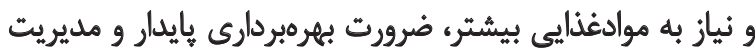

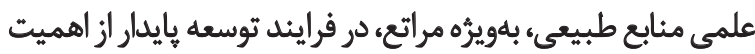
برخوردار است (Khalighi, Khalighi, \& Farahpoor, 2006). بكى برديديد، اين ضرورت ايجاب مى كند كه بهرهورى و وشد بحر بخش منابع طبيعى،

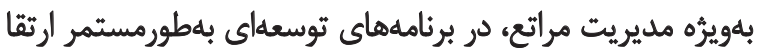

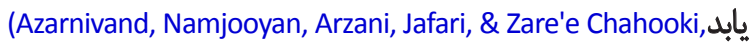
(2007. در نيمقرن اخير، بهدليل شكنيندكى اجتماعي و اقتصادى

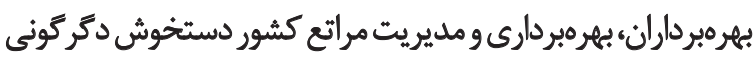
و تغييرات زيادى شله است(Heydari, 2010; Barani, 2004).

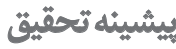

بيشتر مطالعات در زميثه مراتع، بلطورعمده درباره مسائلى

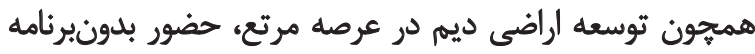

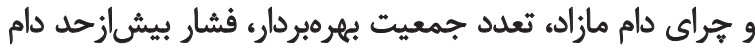

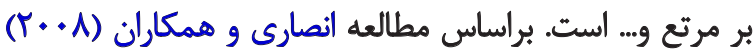
در بررسى عوامل اجتماعى اقتصادى مؤثر بر تخريب مراتع در دران
و برنامهريزان توسعه مطرح شد كه اينكوئه روند رشد اقتصادى،

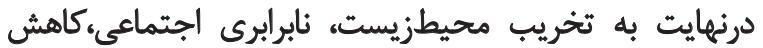

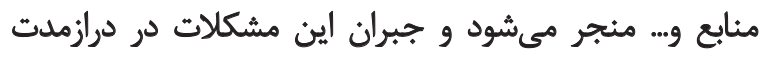
موجب ضررهاى فراوان اقتصادى خواهد مدائ شد (Todaro, 1977).

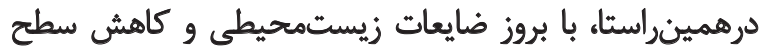

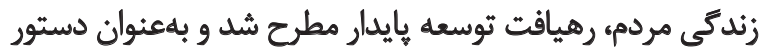

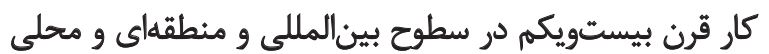
تعيين شد (Roseland, 1977).

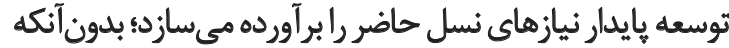

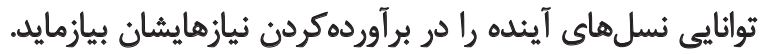

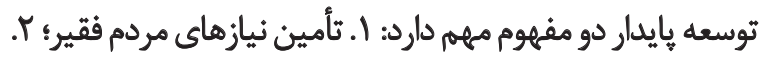

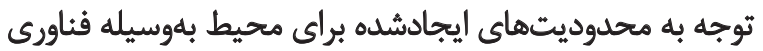

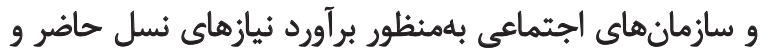

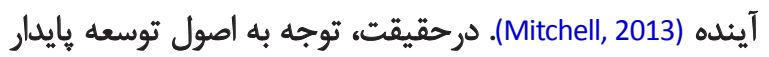
سبب مىشود كه درنتيجه دخالتهاى نابجاي انسان، كمترين

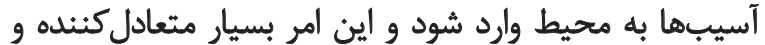

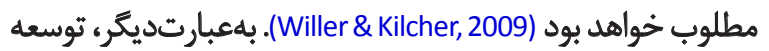

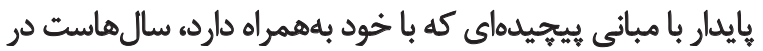
ادبيات جهانى بررسى مى بشود.

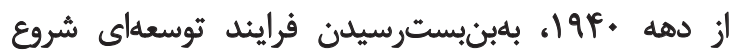

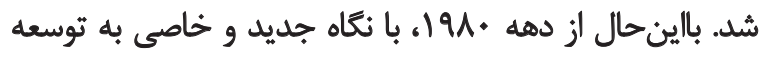

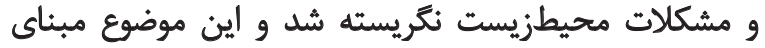

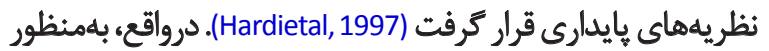

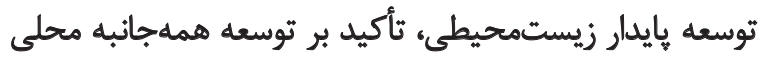

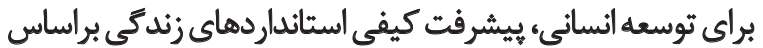
حفظ محيطزيست و توسعه بايدار اجتماعى، اتخاذ رويكرد توسعه مناسب راضرورى مئماياند (Kanamaru, 2005). محدوديتها وظرفيتهاى منطقهاى امروزه، كشورهاى درحالتوسعه بهمنظور تقويت زيربناى

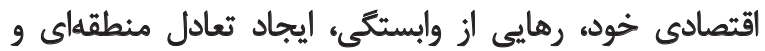

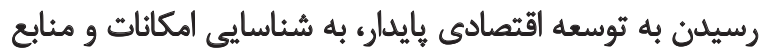

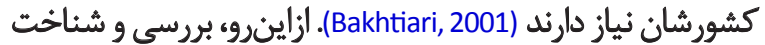

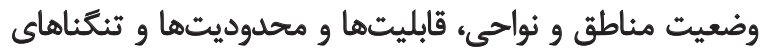

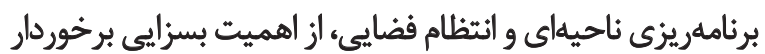

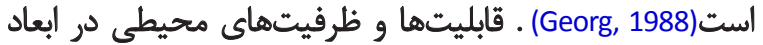

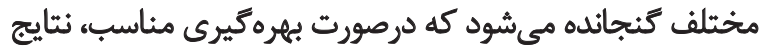

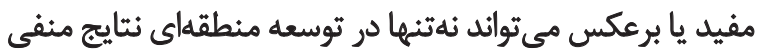
داشته باشد؛ بلكه آثار آن به سطح ملى نئ نيز كشيده شودي تودي براى اينكه ظرفيتهاى بالقوه موجود در هر سيستم بلهورت

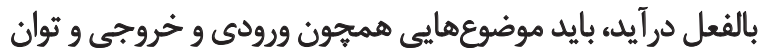

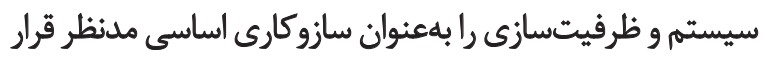


جمعيت، اهالى بومى اين مناطق بهدليل وابستكى شديد به منابع طبيعى و كمبودن فعاليتهاى كشاورزى، با حفظ اكوائ اكوسيستم

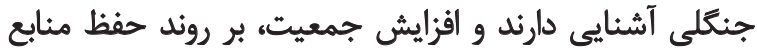

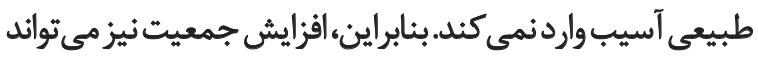
به حفظ منابع طبيعى كمك كند و هميشه تخريب كننده نيست

\section{روش شُناسي تحقيث}

اين تحقيق ازنظر هدف، كاربردى و ازنظر ماهيت،

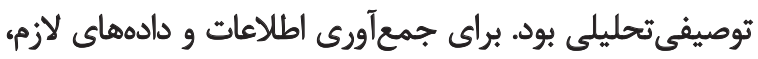

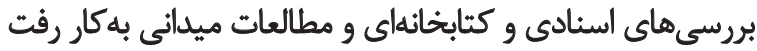

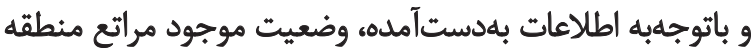

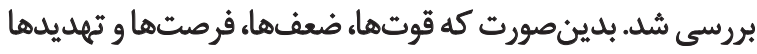

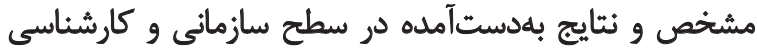

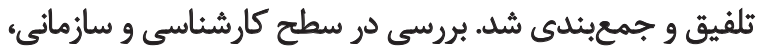

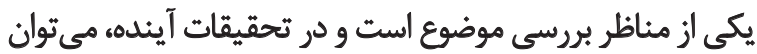
از ديدكاه جامعه و مديران محلى نيز بر اين موضوع تأكيد كرد.

تلفيق و جمعبندى مطالب در هر سطح، با بركزارى

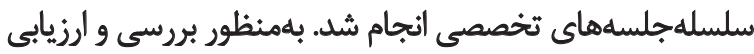

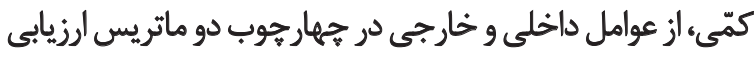

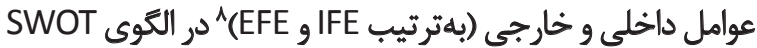

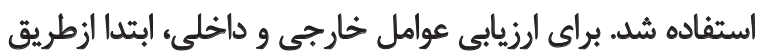

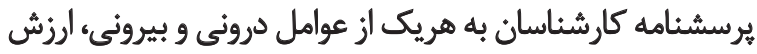

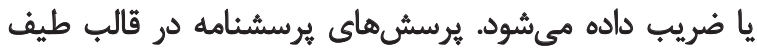

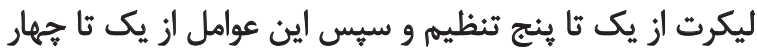

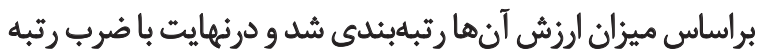

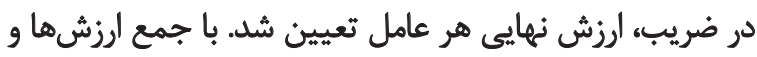

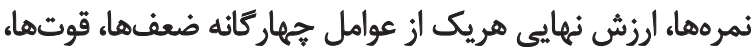

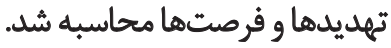

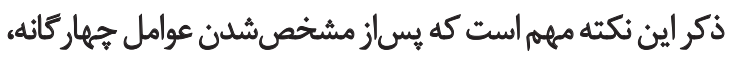

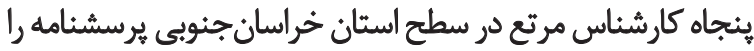

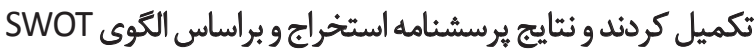

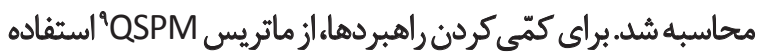

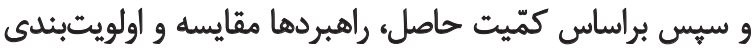

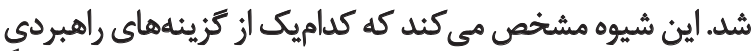

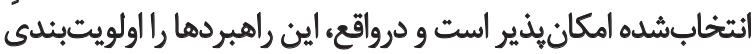

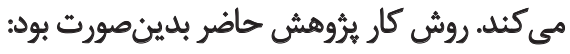

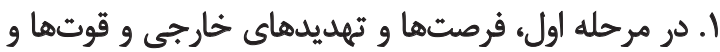

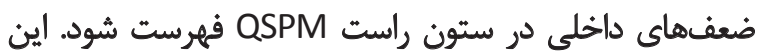

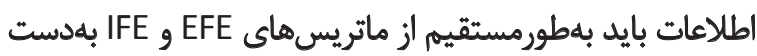

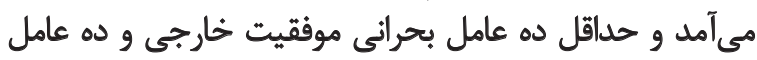

8. Internal Factors Evalution \& Externall Factors Evalution 9. Quantitative Strategic Planning Matrix (QSPM)

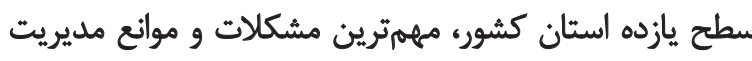

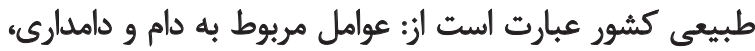

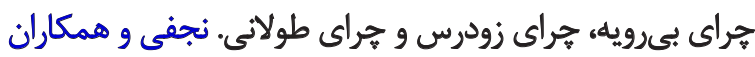

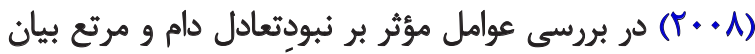

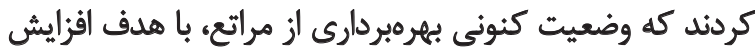

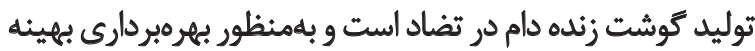
از مراتع، بايد ميزان استفاده از مراتع را كاهش داد دادي

نتايج مطالعه حسينىنسب و همكاران (11· (r) نشان

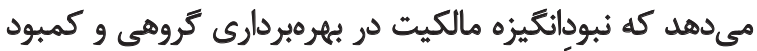

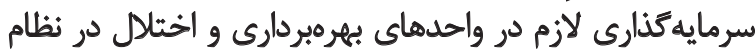

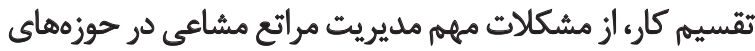

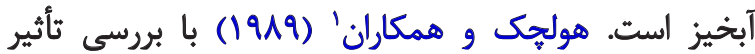

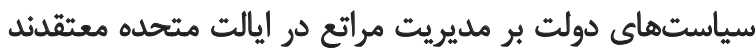

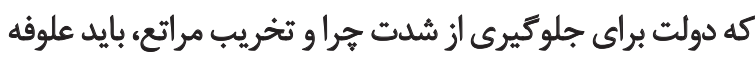

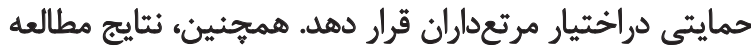

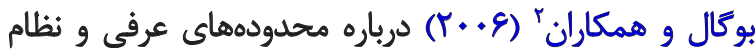

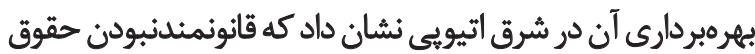

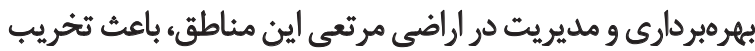
مراتع و فقر بيشتر و كمبود غذا شده است.

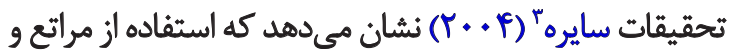

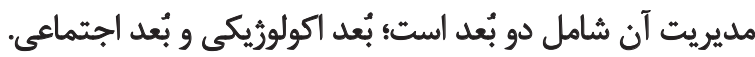

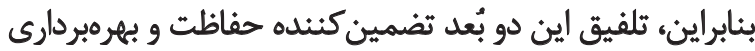

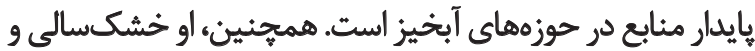

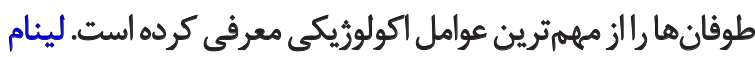

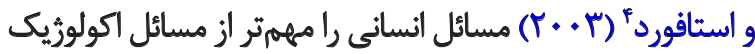

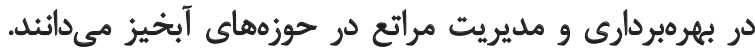

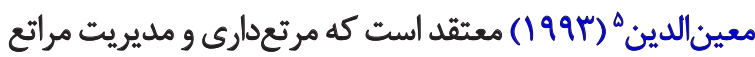

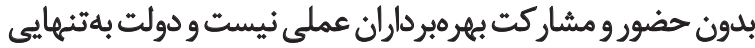

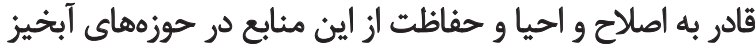

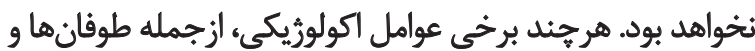
تغييرات اقليمى نيز در اين زمينه نأثير كذار است.

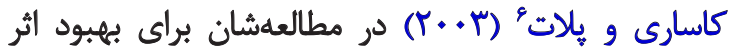

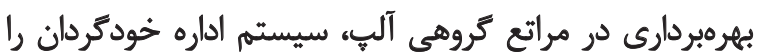

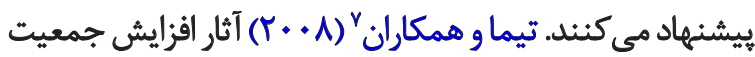

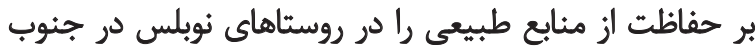

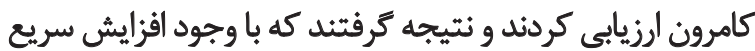

1. Holechek et al.

2. Bogale et al.

3. Sayre

4. Lynam \& Stafford

5. Moeinadan

6. Casari \& Plot

7. Timah et al. 


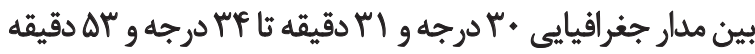

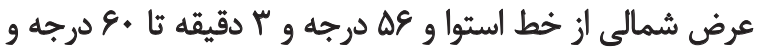
دV دقيقه طول شرقى از نصفالنهار كرينويج قرار كرفته است

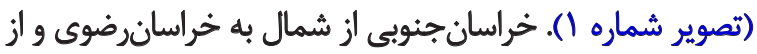

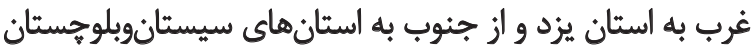

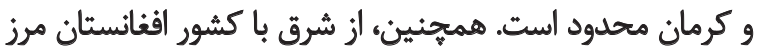

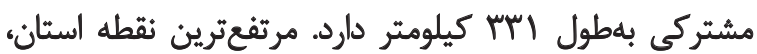

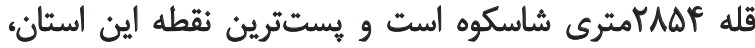

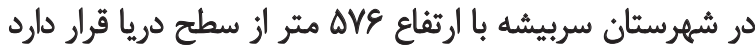

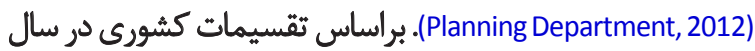

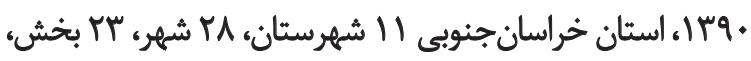

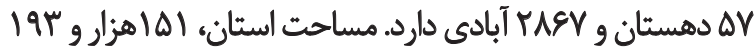

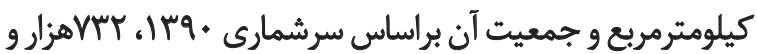

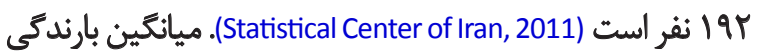

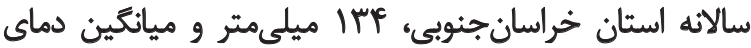
سالانه، IV/D درجه سلسيوس است - The Center of Meteoro

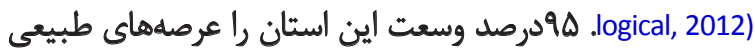
دربرمى

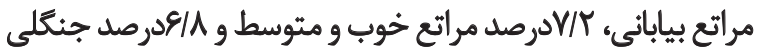

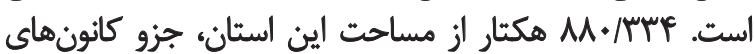
بحراني فرسايش بادى است (Planning Department, 2012).

batiol

درابتدا عوامل جهار كائه قوتها (جدول شُماره 1)، ضعفها
بحرائى موفقيت داخلمي بايد به ماتريس QSPM ارائه مي شدك Y. در مرحله دوم، براي هر عامل بحراني موفقيت امتيازى

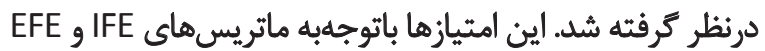

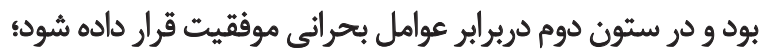
r. در مرحله سوم، با درنظركرفتن مرحله دوم فرمولهكردن,

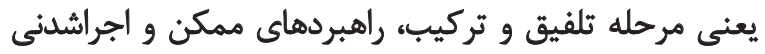

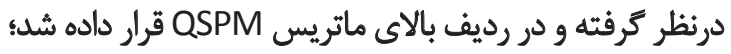

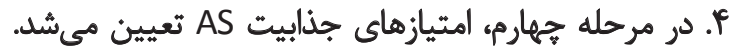
آنها را بهصورت مقادير عددى تعريف مي كنئد كه نشاندهينده

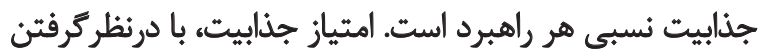

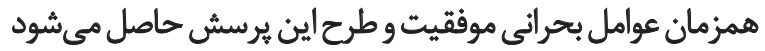

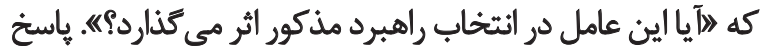

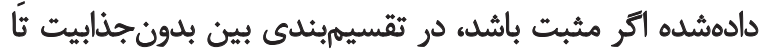

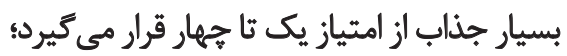
ه. در مرحله بنجمه، جمع امتيازهاي جذابيتها بهدست آورده

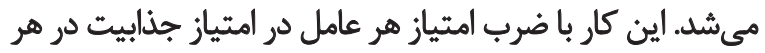

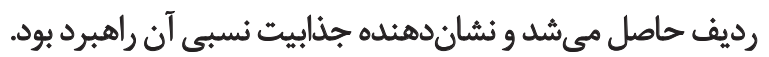

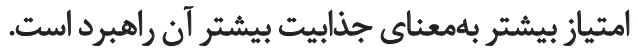

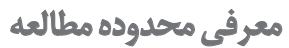
استان خراسان جنوبى تا قبل از ويوستن شهرستان طبس،

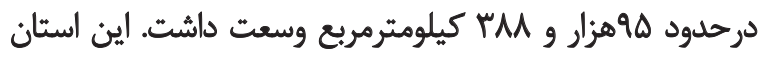

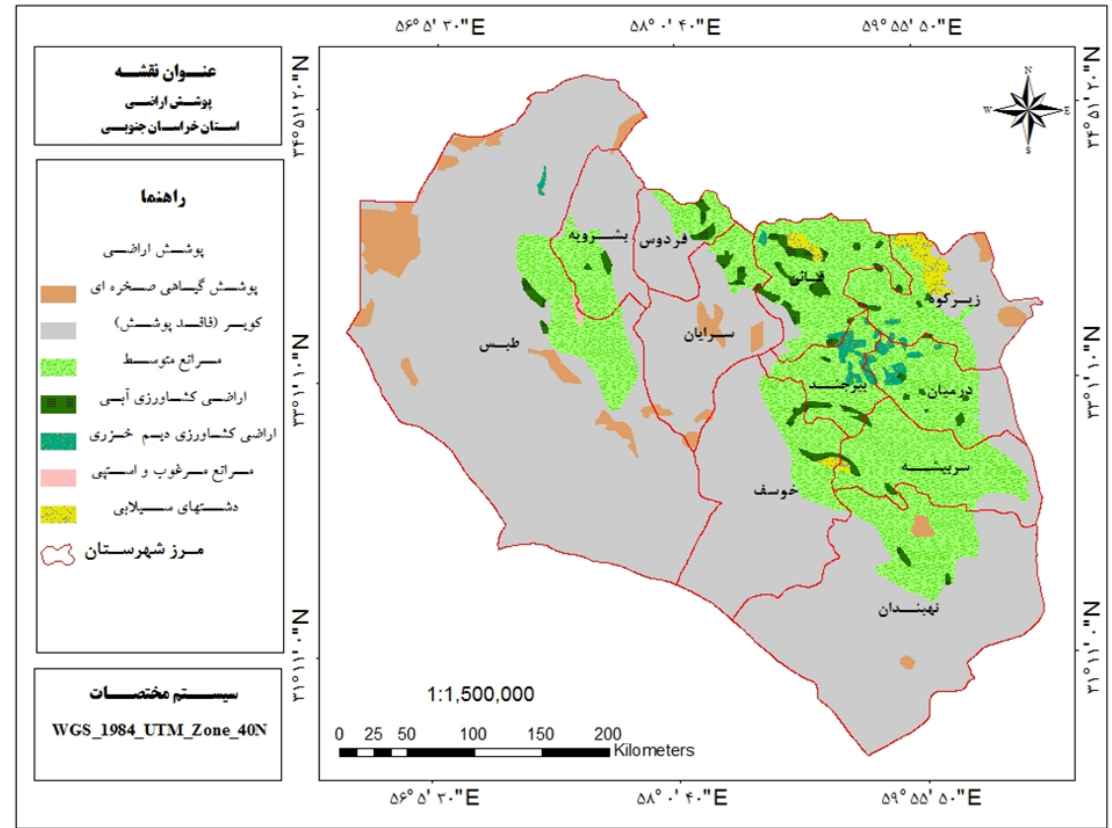


بومى و سنتى در استفاده از روانابهاي سطحى بلمنظور احياى

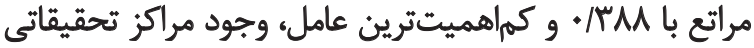

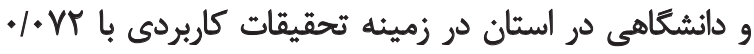

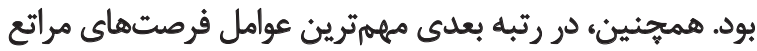

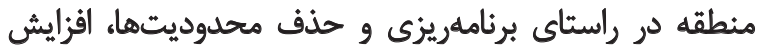

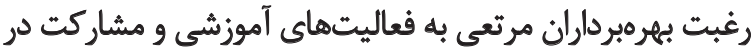

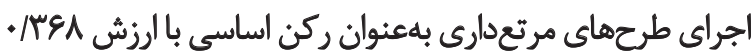

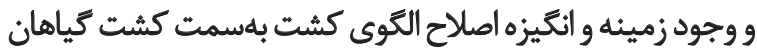

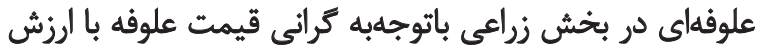

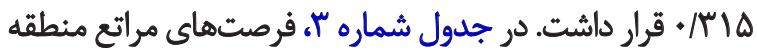

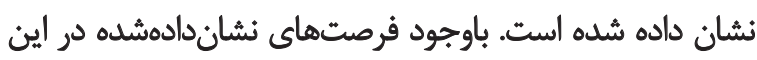

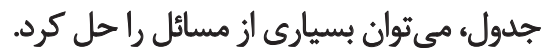

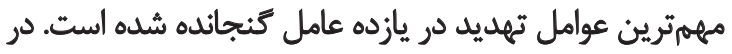

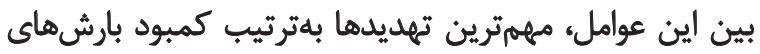

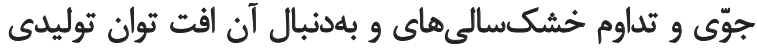

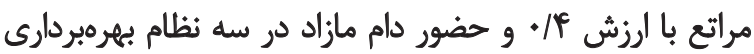

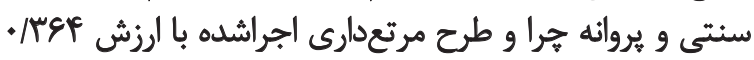

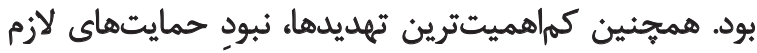

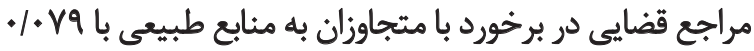

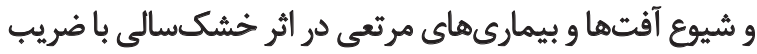

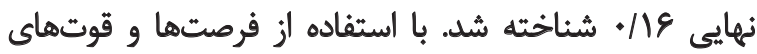

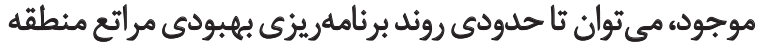
را فراهم ساخت و از روند منفى آنها كاست كاست.
(جدول شماره Y)، فرصتها (جدول شماره ז) و تهلديدهاى

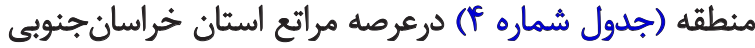

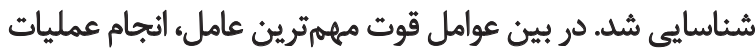

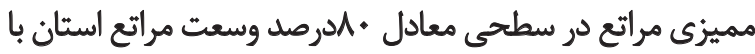

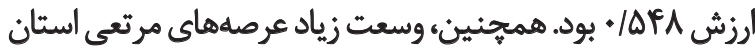

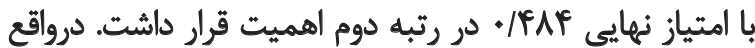

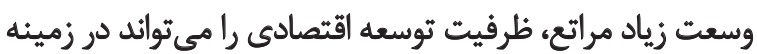

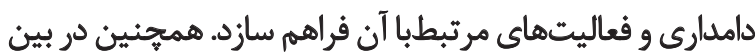

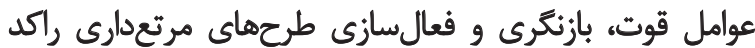

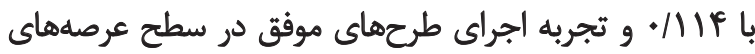

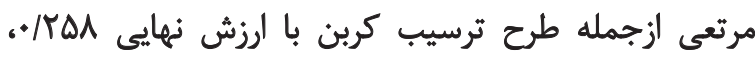

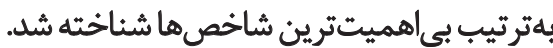

در بين عوامل ضعف مهمترين ضعف، نوع دام غالب در مراتع

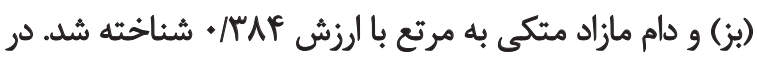

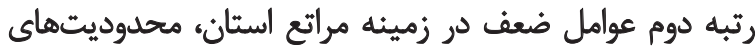

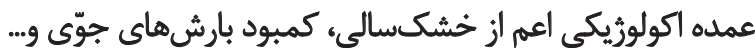

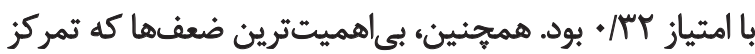

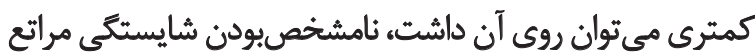

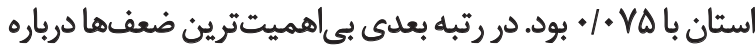

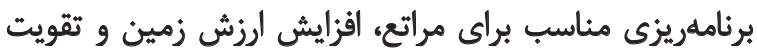

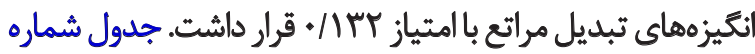

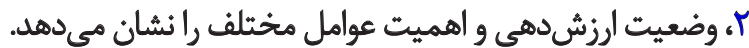
در بين عوامل فرصت مهمترين فرصت، برخوردارى از دانش

جدول ا. عوامل راهبردى درونى (قوتها) (مئبع: يافتههاي تحقيق، هوبrا)

\begin{tabular}{|c|c|c|c|c|c|}
\hline ضريب نهايى & رتبه & ضريب ثائويه به صدم & ضريب ثانويه & ضريب اوليه & ماتويس ارزيابى عوامل داخلى IFE (قوتثها) \\
\hline - IAfa & $p$ &.$/ 1 m$ & $I r / N$ & 10 & 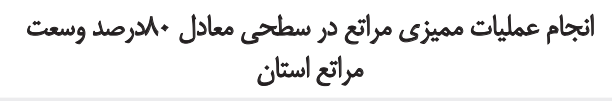 \\
\hline.$/ M F$ & 1 &.$/ I f F$ & $11 / F$ & $n$ & بازنكرى و فعال سازى طرحهاى مرتعدارى راكد \\
\hline . & r & / & $11 / \pi$ & v. & غناى قراوان كونههاي كياهي دارويى و صنعتى و اهكان أستفاده \\
\hline.$/ M r$ & $r$ &.$/ N F$ & $\mid r / F$ & $w$ & توجه كافى به حفظ كونهاى مرتعى و وسعت زياد عرصههاى \\
\hline - /FAF & f &.$/ M I$ & $I r /$ & VA & وسعت زياد عرصههاى مرتعى استان \\
\hline - /TAA & r &.$/ 1 r$ & $I r / q$ & A. & تجربه اجراى طرحهاى موفق در سطح عرصههاى مرتعى ازجمله \\
\hline.$/ T \Delta V$ & $r$ & .111 & $11 / 9$ & $n$ & تهيه طرحهاى مرتعدارى در سطح درخورتوجهى أز عرصههاى \\
\hline.$/ M T$ & r &.$/ 1 F$ & $1 \% \%$ & AV & حضور كونههاى كياهى بومى مثاوم به تنشهاى محيطى \\
\hline r/A9 & - & 1 & $1+$. & 819 & جمع \\
\hline
\end{tabular}


جدول Y عوامل راهبردي درونى (ضعفها) (منبع: يافتههاي تحقيق، هوبr)

\begin{tabular}{|c|c|c|c|c|c|}
\hline ضهريب & وتبه & ضريب ثانويه & ضريب & ضريب اوليه & ماتريس الرزيابي عواهل داخلي IFE (ضعفها) \\
\hline . & $r$ & 1.98 & g/sq & 81 & افزايش الرزش زمين و تقويت انكيزههاى تبديل مراتع \\
\hline - /raf & $f$ & $\cdot 1 \cdot n$ & $V / M A$ & $n^{m}$ & جمعيت زياد بهرهبردار روستاييى و عشايرى \\
\hline.$/ M 19$ & $r$ & $\cdot 1 \cdot n^{\infty}$ & $\mathrm{V} / \mathrm{TA}$ & Vo & هشاعبودن بهرمبردارى از هراتع \\
\hline AKR/ & $r$ & $.1 \cdot v e$ & V/FV & $V A$ & نظام دامدارى ستتى و هعيشتى و وابسته به بهرهبردارى ازٔ مراتع \\
\hline.$/ N T$ & r & $\cdot 1 \cdot n$ & $V / M$ & $n^{m}$ & ادامه بوتهكني براى مصارف كوناكون سوختى \\
\hline . /rar & r & $\because 1+A V$ & $V / V \Delta$ & 19 & نوع دام غالب در مراتع (بز) و دام مازاد متكى به مرتع \\
\hline.$/ \pi T$ & $f$ & 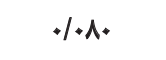 & $N \cdot V$ & Ar & محلوديتهاي اكولوريكي اعم از خشكسالى و بارش \\
\hline$+1+\mathrm{Va}$ & 1 & I.VA & $V / \Delta Y$ & $w$ & نامشخصبودن شايستكى مراتيع استان \\
\hline ./1AS & r & $\% V A$ & V/AV & A. & همسو و هماهنى و هلفمندنبودن حمايتها در سه بخش مرتع و دام و علوفه \\
\hline$+|+1|$ & 1 & $\cdot|+\lambda|$ & NIS & Ar & هماهنكـنبودن دستكاههاى اجرايى در عرصه مثابع طبيعى \\
\hline.$/ V$ & r & $\cdot 1 \cdot 1 \Delta$ & $N \Delta$ & AV & هشخصنيودن جايكاه ارزشها و خدمات اكولوزيكى و زيستمحيطى هراتع \\
\hline . & $r$ & $1 \cdot 19$ & V/av & A) & كمبود ميزان سرمايهكثارى در بخش هنابع طييعى \\
\hline & r & $.1 .8 A$ & $g / M$ & $\mathrm{ve}$ & رغبتأنداشتن هرتعداران به بيمه مراتع \\
\hline$r / \Delta S$ & - & 1 & $1 .$. & 1.18 & 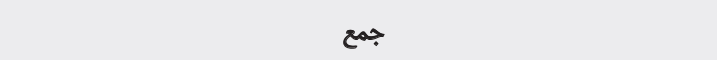 \\
\hline
\end{tabular}

年

راهبردهاي رقابتى WO (ضعفها و فرصتها)

نوع دوم راهبردها، تركيبي از فرصتها و ضعفها بود؛ يعني

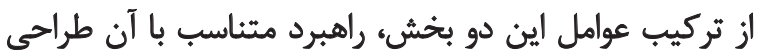

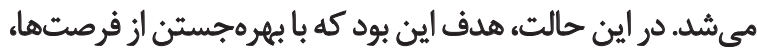

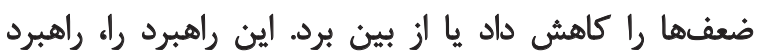

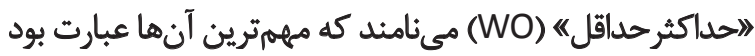

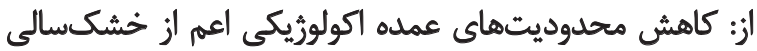

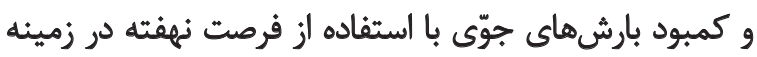

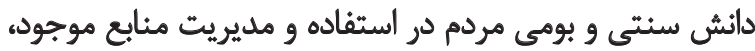

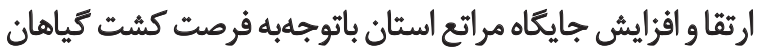

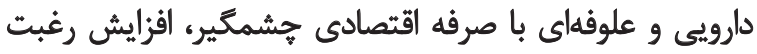

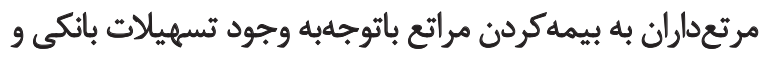

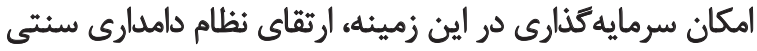

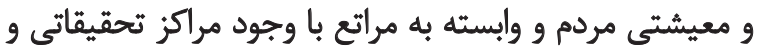

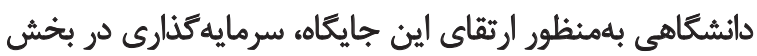

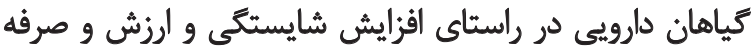

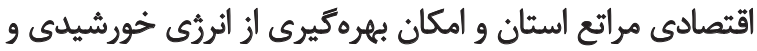

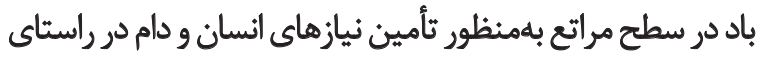
كاهش محدوديتهاي عمده اكولوزيكى و افزايش جايكاه انسائى.

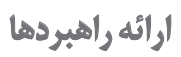

يساز مشخص كردن عوامل دروني و بيروني و تعيين ارزش هر ير

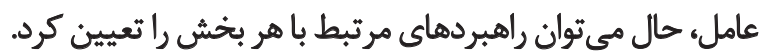

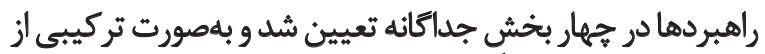

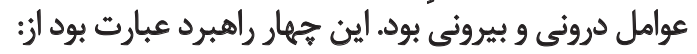

\section{راهبردهاي تهاجمي SO (قوتها وفرصتها)}

نوع اول راهبردها، راهبردى بود كه در آن با استفاده از قوتها،

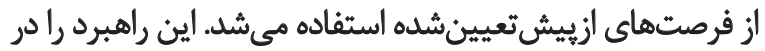

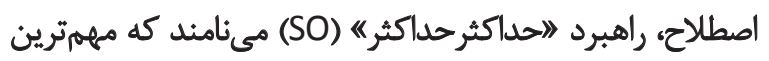

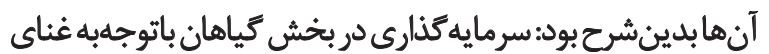

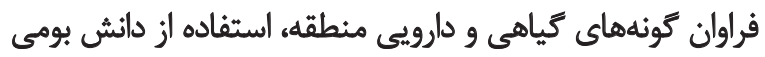

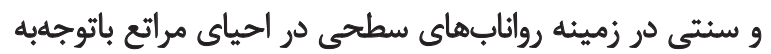
وسعت زياد عرصههاى مرتعي استان، وجود امكائات و شرايط زيطي

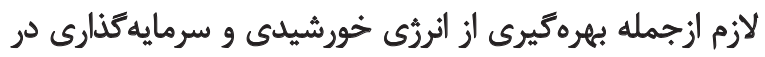

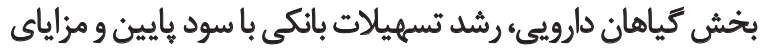

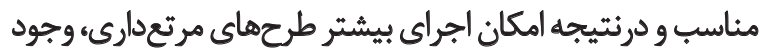

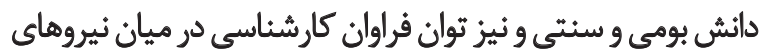
اجرايى و توجه بيشتر به كونهائ كياهي مقاوم. 
جدول لا. عوامل راهبردى بيروئى (فرصتها) (منبع: يافتههاي تحقيق، هوبا|)

\begin{tabular}{|c|c|c|c|c|c|}
\hline ضبريب - مبيى & رتبه & ضريب ثانويه & خريب & ضريب اوليه & ماتريس ارزيابى عوامل خارجى EFE (فرصتها) \\
\hline$\cdot \pi$ & r & +11. & $1+1 \cdot r$ & ve & توان كارشناسى نيروهاي اجرايع و متخصص استان \\
\hline . TVE & r & .1 .94 & qur & r. & اهكان اجراى طرحهاي متعلد در سطح مراتع استان \\
\hline.$/ V_{T}$ & 1 & $\cdot 1 \cdot n$ & V/TE & $\Delta \Delta$ & وجود هراكز تحقيقاتيى و دائشكاهى در استان \\
\hline • / M M & p & .1 .98 & q/W & $n^{e}$ & برخوردارى از دانش بومى و سنتى در استفاده از روانابهاي سطحى براى احياى مراتع \\
\hline.$/ T M$ & r & .1 .98 & Vep & $r^{m}$ & امكان بهرهكيرى از انرزى خورشيد، باد و... \\
\hline . TeF & r & $\% M$ & NAS & eV & 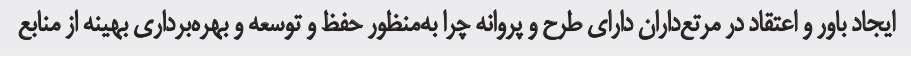 \\
\hline.$/ 48$ & p & .1 .94 & que & r. & 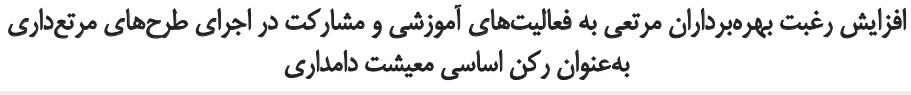 \\
\hline . & $r$ & .1 .89 & V/ar & 9. & امكان سرمايه كذارى در بخش كياهان دارويى \\
\hline . & $r$ & $+N \cdot \Delta$ & $1 . / 0$ & A. & وجود زمينه و انكيزه اصلاح الكوى كشت بلسمت كشت كياهان علوقهاى در بخش زراعى \\
\hline$+/ T r q$ & $r$ & $+/ .94$ & $q / T$ & $n$ & امكان توسعه كازرسانى به مناطق روستايى و جايكزينى سوخت فسيلى بهجاى سوخت هيزمى \\
\hline$* / 1 \varepsilon$ & $r$ & $+1+1$. & $N \cdot \Delta$ & 81 & رشد تسهيلات بانكي با سود بايين براى مشاغل جانبي بهرهبرداران بلمنظور كاهش فشار دام در \\
\hline r/Af & $=$ & 1 & $1 .$. & VAY & جمع \\
\hline
\end{tabular}

تحلئم

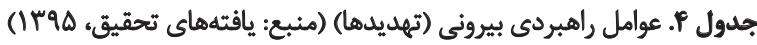

\begin{tabular}{|c|c|c|c|c|c|}
\hline 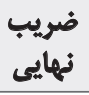 & رتبه & ضريب ثانويه & ضريب & ضريب اليه & ماتريس ارزيابى عوامل خارجى EFE (تهديدها) \\
\hline - Irep & $p$ & .1 .91 & Q/V & ve & حضور دام مازاد در سه نظام بهرهبردارى سنتى و يرواثه هرا و طرح مرتعدارى اجراشده \\
\hline ./Mr & $r$ & .1 .91 & Q/IV & ve & انقراض كُونههاى كياهى بومى \\
\hline.$M \cdot Q$ & $r$ & $\cdot 11 \cdot r$ & $1 \cdot /{ }^{\prime} A$ & $N$ & وجود شكاف عميق بين بنش آهوزش و يروهش و اجرا در عرصهاي منابع طبيعى \\
\hline .118 & $r$ & 1.1. & $N \cdot q$ & ov & ادامه روند بوتهكنى از مراتع باتوجهبه اقزايش قيمت نهادههاي سوختى \\
\hline $1+19$ & 1 & $1+\sqrt{9}$ & V/ar & 98 & ثيود حمايتهاي لازم مراجع قضايي در برخورد با هتجاوزان به منابع طبيعى \\
\hline$\cdot / 4$ & $p$ & .11. & $1.1 . r$ & $A r$ & كمبود بارش هاى جوى و تداوم خشكسالمىها و بهدنبال آن افت توان توليدى مراتع \\
\hline - /TAS & $r$ & .1 .90 & V/AF & va & 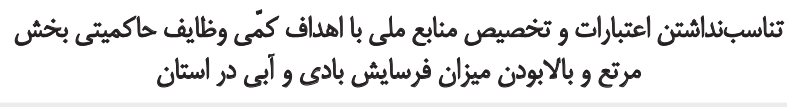 \\
\hline . /TAT & $r$ & 1.98 & Q/er & VA & بالابودن هيزان فرسايش بادى و آبى در استان \\
\hline.$/ 791$ & $r$ & 1.97 & $9 / 21$ & 1) & توسعه مناطق بحرائي فرسايش بادى بلهدليل خشكسالى \\
\hline \% & 1 & $\cdot / \cdot \Lambda r$ & NMr & eq & شيوع آفتها و بيمارى هاى مرتعى در اثر خشكسالى \\
\hline.$/ 18$ & $r$ & $1+1$ & $N \cdot q$ & eV & تخريب مراتع براى تملك عرفى بر اراضى \\
\hline$T / \Delta A$ & - & 1 & $1 .$. & AYA & جمع \\
\hline
\end{tabular}


تصوير r. ماتريس SWOT و نحوه تعيين راهبردها (منبع: يافتههاي تحقيق، هوبr)

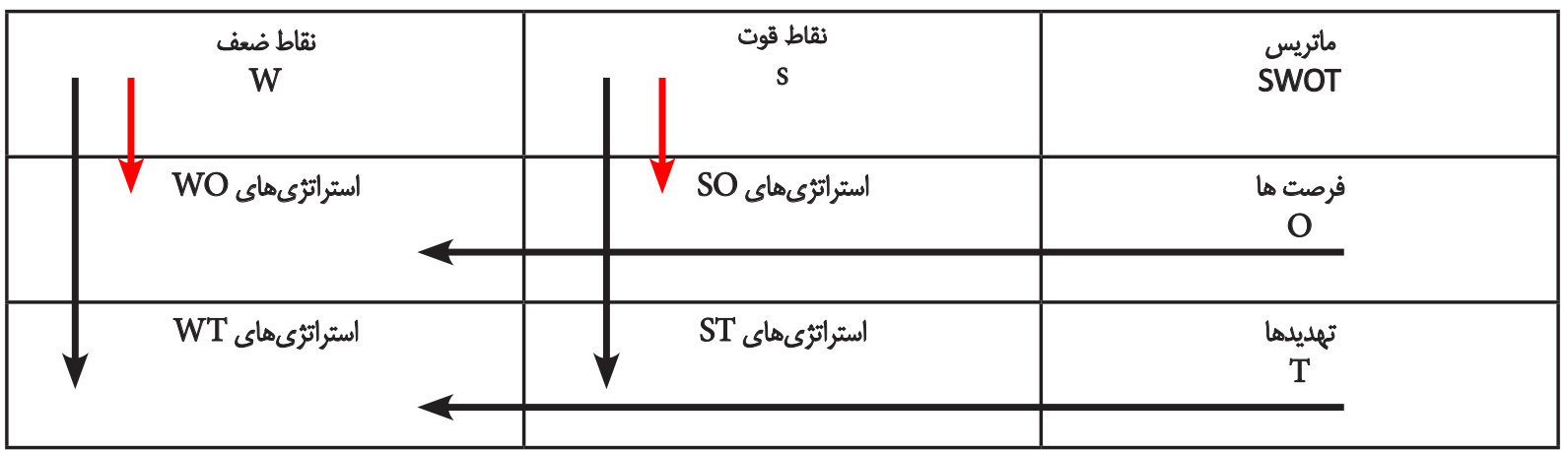

:

از مجموع ضرايب نهايي عوامل بهدست مي آمد. براساس تصوير شماره

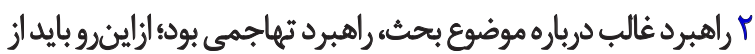

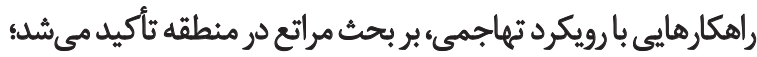

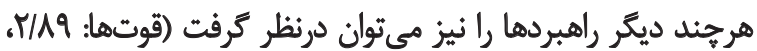

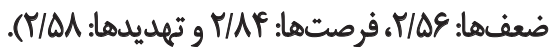

الولويتبثنى راهبروها با استثاده از ماتريس QSPM براي كتمىكردن راهبردها، ماتريس QSPM بهكار رفتي؛

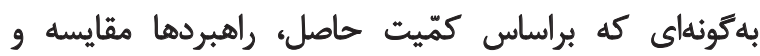

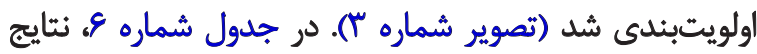

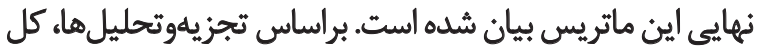

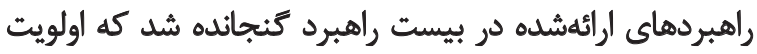

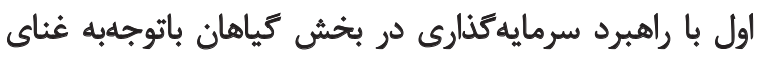

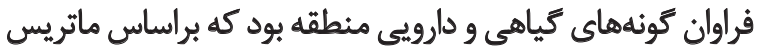

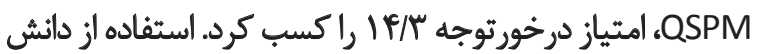

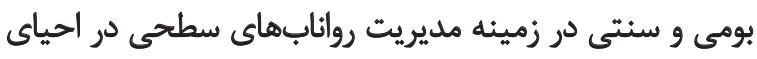

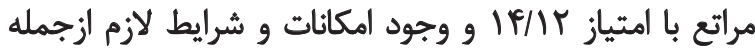
انرزى خورشيدى و سرمايهكذارى در بخش كياهان بان بان امتياز

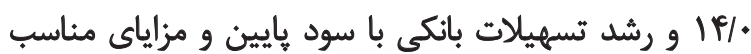

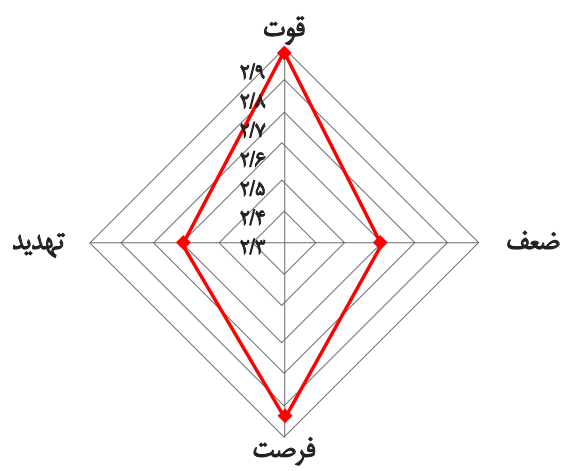

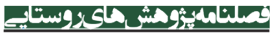

تصوير ب. ماتريس ارزيابي موقعيث و اقدام راهبردى (منبع: يافتهاي ثحقيق، هوبرا)

\section{راهبردهاى محافظه كارانه ST (تهديدها و قوتها)}

نوع سوم راهبرد، تركيبى از قوتها و تهديدها بوداد. در اين حالت،

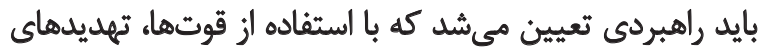

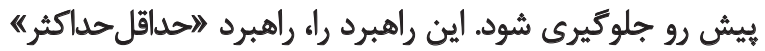

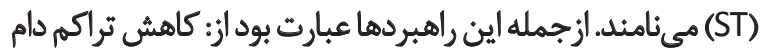

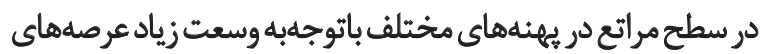

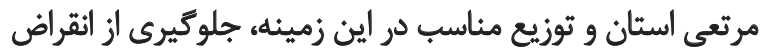

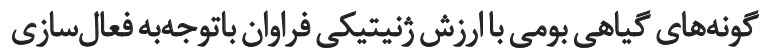
طرحهاى مرتعدارى راكد و اجراى طرحمائي

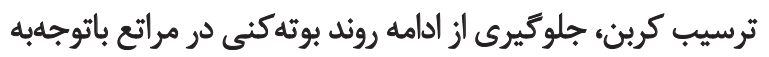

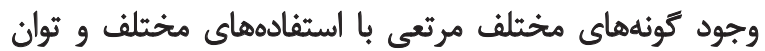

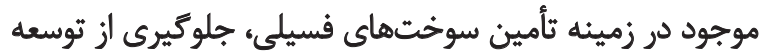

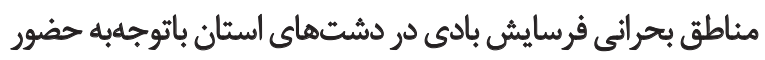

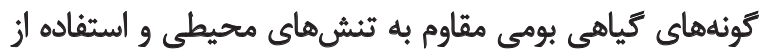

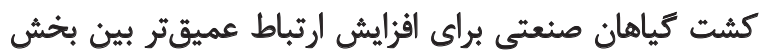

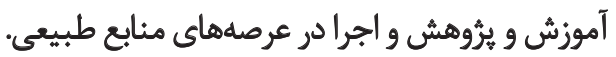

راهبردهاي تدافعى WT (تهديدها وضعفها)

نوع جهارم راهبرد، تركيبى از ضعفها و تهديدها بود. در اين

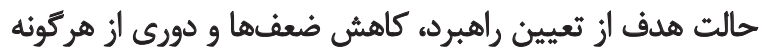

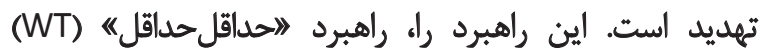

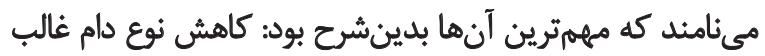

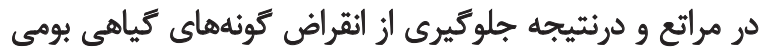

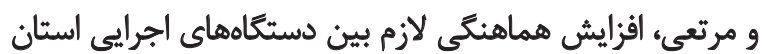

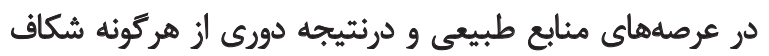

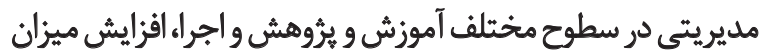

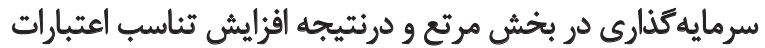

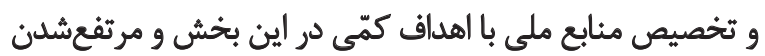

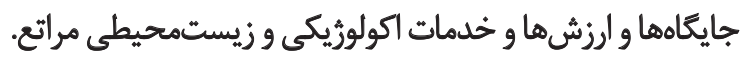
براي تعيين راهبرد مناسب در زمينه مراتع منطقه، از ضريب نهايى

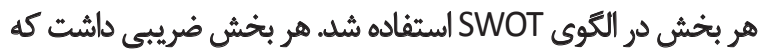


داخلى و خارجى، اعم از فرصتها، تهايدها، قوتها و ضعفهاء

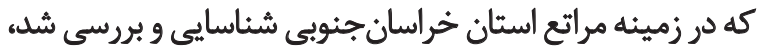

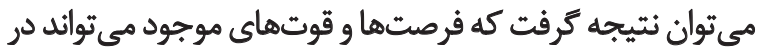

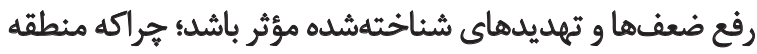

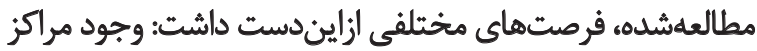

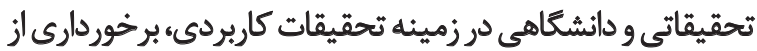

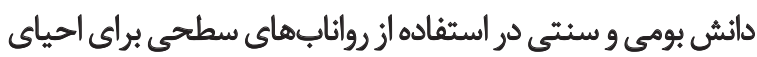

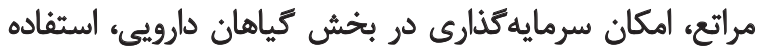

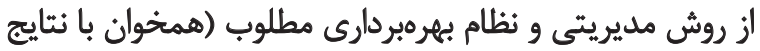

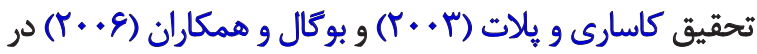

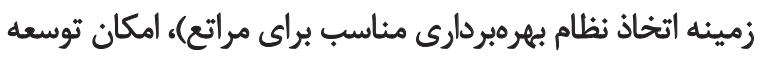

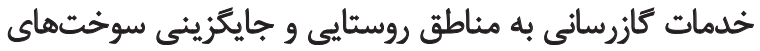

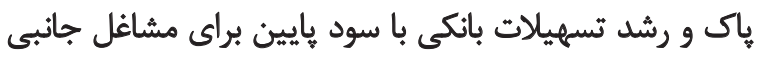

با امثياز ه/M ا، در رتبههاى بعدى اولويت قرار كرفت. ازنظر

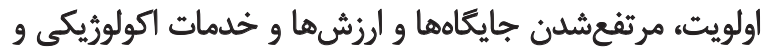

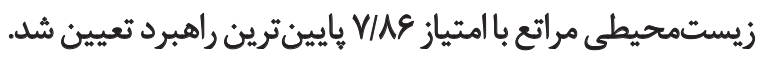

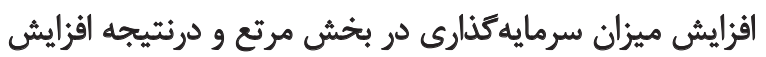

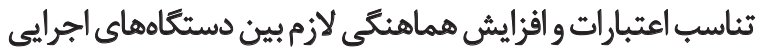

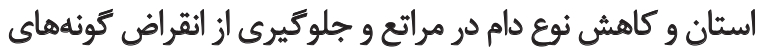

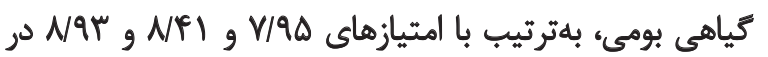

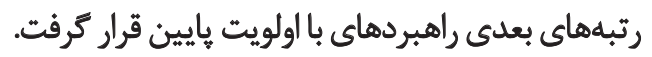

\section{بحث و تثيجيكيرى}

در بحث مراتع استان خراسانجنوبى عوامل مختلفى، جهانه

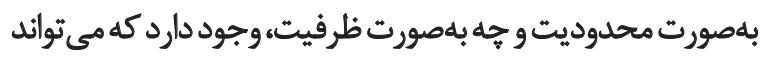

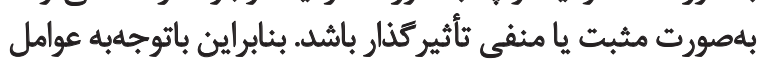

جدول و اولويتبثلى مهمترين راهبردهاي مديريت بايدار مراتع استان خراسانجنوبى (منبع: يافتههاي تحقيق، هوبا)

\begin{tabular}{|c|c|c|}
\hline QSPM & عنوان راهبرد براساس اولويت & رديف \\
\hline $\mid f / r$ & سرمايه كذارى در بخش كياهان بائوجهبه غناى فراوان كونهاي كياهى و دارويى منطقه & 1 \\
\hline $\mid F / r$ & استفاده از دانش بومى و سنتى در زمينه رواثابهاى سطحى در احياى مراتع & $r$ \\
\hline $1 \%$ & وجود امكانات و شرايط لازم ازجمله اثرأى خورشيدى و سرمايهذازي در بخش كياهان & $r$ \\
\hline $1 r / \lambda$ & رشد تسميلات بانكي با سود هايين و مزاياى مناسب & i \\
\hline $1 r / N$ & وجود دانش بومى و ستى و همجنين توان جشمكير كارشناسى & $\Delta$ \\
\hline $1 Y / \Delta$ & كاهش محدوديتهاي عمده اكولوريكى & $\&$ \\
\hline $\mid r / r$ & امكان بهرهكيرى از اثرثى هاى خورشيدى و بادى در ثأمين نيازهاى انسانى و... & $r$ \\
\hline $11 / f$ & توجه بيشتر به بخش كياهان دارويى & 1 \\
\hline $11 / 1$ & افزايش جايكاه مراتع استان باثوجلهيه فرصت كشت كياهان دارويع. & 9 \\
\hline $11 \%$ & كاهش دام و مازاد متكى به مراتع با استفاده از فرصت تسهيلات بانكىى & 1. \\
\hline $1 . / 0$ & افزايش رغبت مرتعداران بله بيمه مراتع باتوجهبه وجود تسهيلات بانكى & 11 \\
\hline $1 . / 4$ & كاهش حضور دام در سطع مراتع در بهنههاي مختلف & ir \\
\hline $1 . / r$ & جلوكيرى از أقراض كونههاي كياهى بوهى با ارزش ذرئيكى & ir \\
\hline V/19 & 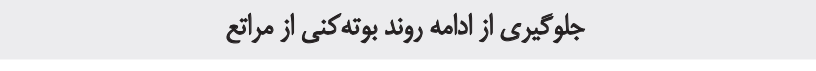 & if \\
\hline$q / P$ & جلوكيرى از توسعه مناطق بحرائى فرسايش بادى & 10 \\
\hline V/P & استفاده از كشت كياهان صنعتى & 18 \\
\hline NAT & كاهش نوع دام غالب در مرائع و درنيّيجه جلوكيرى از اتقراض كونههاي كياهي بومى & iv \\
\hline$N F i$ & افززايش هماهنكى لازم بين دستكاههاى اجرايى استان & IA \\
\hline V/qه & افزايش ميزان سرمايهكثارى در بخش مرتع و درنتيجه افزايش ثناسب اعتبارات & 19 \\
\hline$V / N$ & مرتفعشن جايكاهها و ارزش ها وخدمات اكولوزيكى و زيستمحيطى مراتع & r. \\
\hline
\end{tabular}


از تحقيق حاضر همخوانى دارد. در اين بخش، سرمايه كذارى در

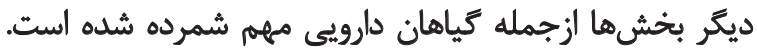

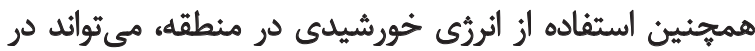

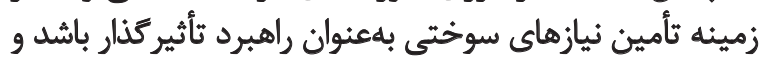

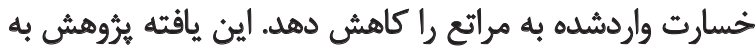

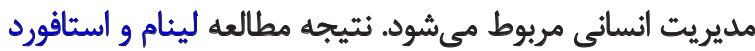

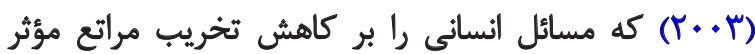

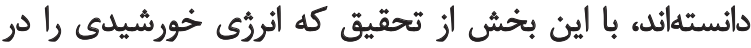

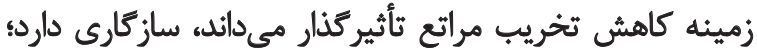

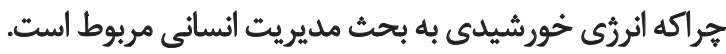

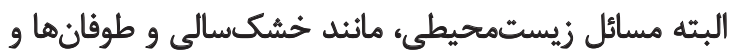
مسائلى ازايندست راكه بيشتر از شرايط اقليمى تأثير مى يذئيردي

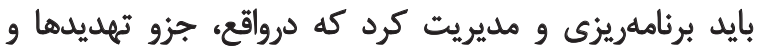
ضعفها بهشمار ميرود. نتايج تحقيقات معين الدين (1991)

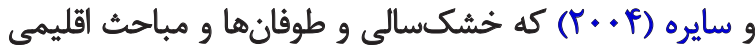

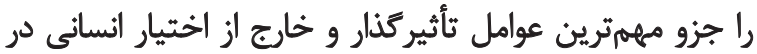

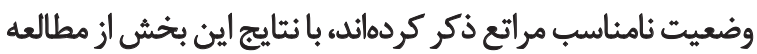

حاضر مطابقت دارد.

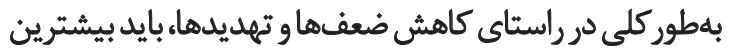

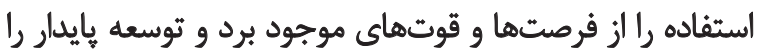

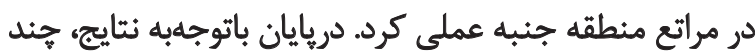
ييشنهاد در زمينه مراتع منطقة ارائه مىشود:

1. استفاده از راهبرد تهاجمى و تمركز بيشتر روى راهكارهاي

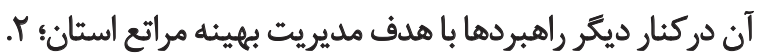

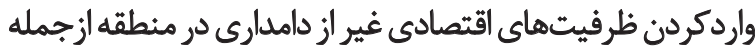

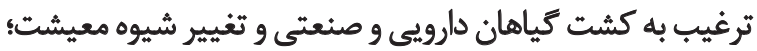

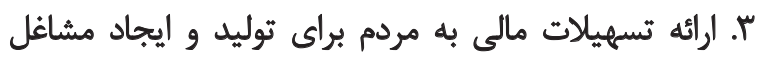

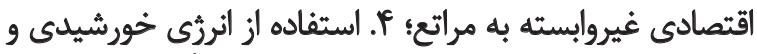

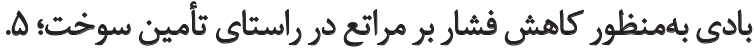

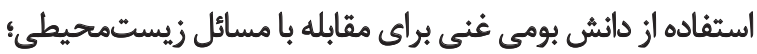

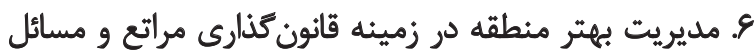

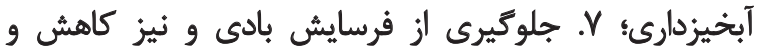

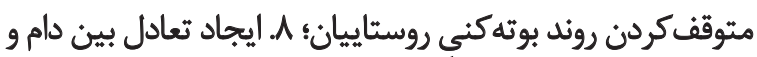

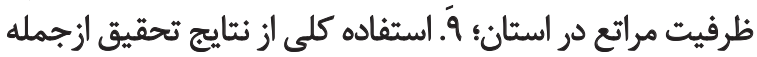
راهبردها و اولويتبندى آنها.

$$
\text { تشكر وقدرواني }
$$

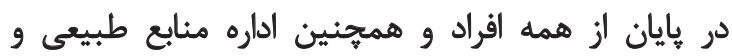

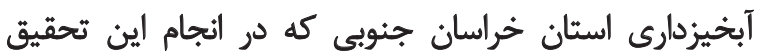

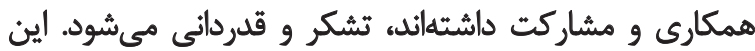
يُؤهش حامى مالى نداشته است.
بهرهبرداران بامنظور كاهش فشار دام در مراتع.

افزونبراين قوتهايى ازايندست از ويرُكى هاي مهمي بود كه

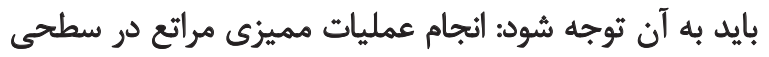

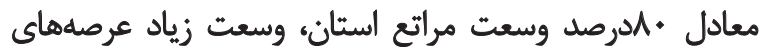

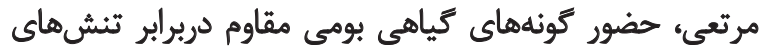

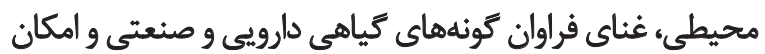

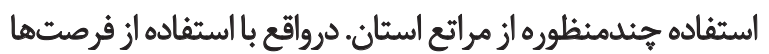

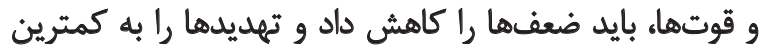

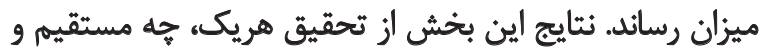

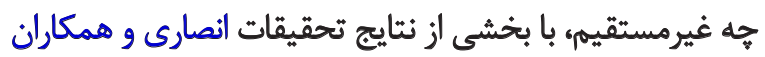

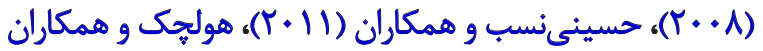

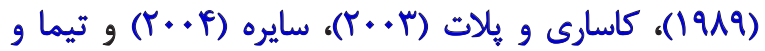

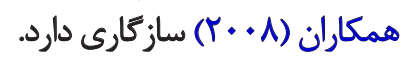

موضوع مهم در منطقه مطالعهشده اين است كه مشكلات

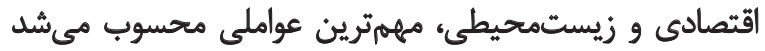

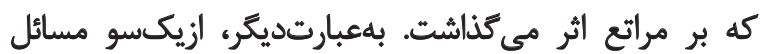

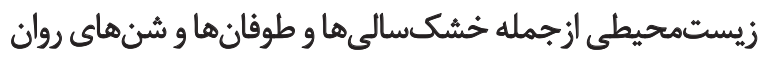

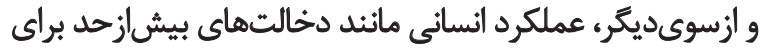

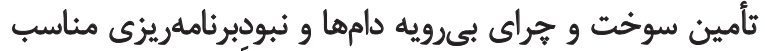

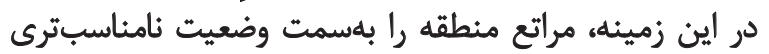

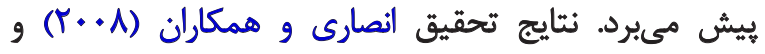

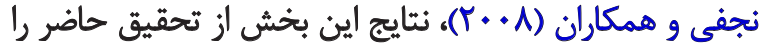

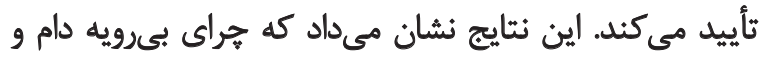
نبودبر نامهريزى بر نامناسبشد اين مران مراتع مؤثر بود.

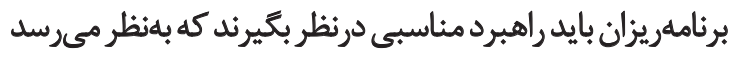

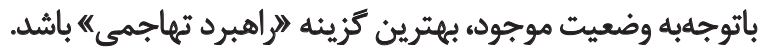

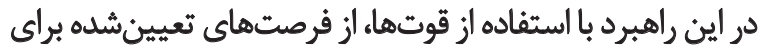
بهرهورى و ارتقاى جايكاه سيستم (مراتع) استفاده مى فيودي؛ يعنى

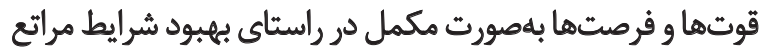

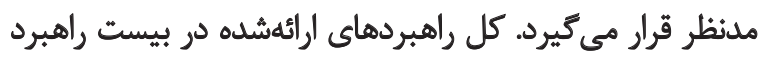

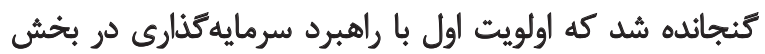

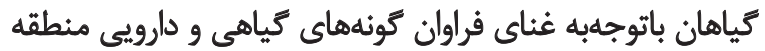

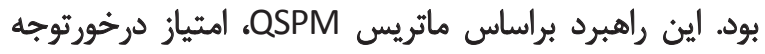

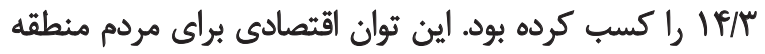

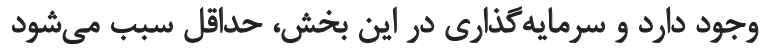

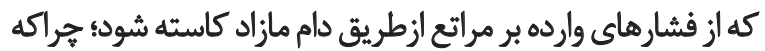

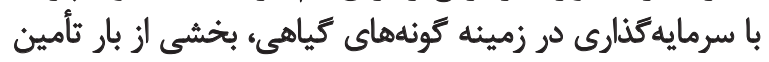

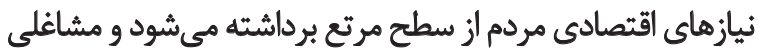

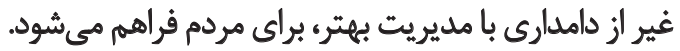
تحقيق حسينى نسب و همكاران (1 + + () نشان مي دهد كمبود

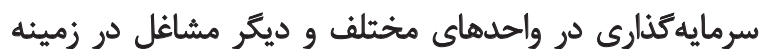

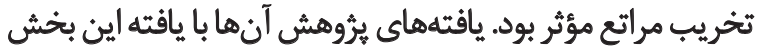




\section{References}

Akbarzadeh, M., \& Mirhaji, T. (2006). [Vegetation changes under precipitation in Steppic rangelands of Rudshur (Persian)]. Iranian Journal of Range and Desert Research, 13(3), 222-35.

Ansari, N., Akhlaghi, J., Ghasemi, M. H. (2008). [ Determination of socio-economic factors on natural resources degradation of Iran (Persian)]. Iranian Journal of Range and Desert Research, 15(4), 50824.

Archer, S. (1990). Development and stability of grass/woody mosaics in a subtropical savanna parkland, Texas, USA. Journal of Biogeography, 17(4-5), 453-62. doi: 10.2307/2845377

Azarnivand, H., Namjoyan, R., Arzani, H., Jafari, M., \& Zare Chahouki, M. A. (2007). [Localization of range improvement plans using GIS and comparing with suggested projects of range management plans in Lar Region (Persian)]. Journal of Rangeland, $1(2), 159-69$

Bakhtiari, S. (2001). [Comparative analysis of the industrial Development provinces of the country (Persian)]. 18. Iranian Journal of Trade Studies, 6(22), 157-86.

Barani, H. (2004). [Reckoning an analyzing of custom orders in order to range management unites (Persian)]. Paper presented at The $3^{\text {th }} \mathrm{In}-$ ternational Congress of Range and Range Management, Tehran, Iran, 8-10 August 2004

Bogale, A., Taeb, M., \& Endo, M. (2006). Land ownership and conflicts over the use of resources: Implication for household vulnerability in eastern Ethiopia. Ecological Economics, 58(1), 134-145. doi: 10.1016/j.ecolecon.2005.07.002

Casari, M., \& Plott, C. R. (2003). Decentralized management of common property resources: Experiments with a centuries-old institution. Journal of Economic Behavior \& Organization, 51(2), 217-247. doi: 10.1016/s0167-2681(02)00098-7

Center of Meteorological of South Khorasan Province. (2012). [Statistical annals (Persian)]. Birjand: Center of Meteorological.

Eskandari, N., Alizadeh, A., Mahdavi. F. (2008). [Policies of range management in Iran (Rangeland technical office) (Persian)]. Tehran: Pooneh press.

Georg, V. (1988). Wealth, poverty and starvation. New York: St. Martins Press.

Hardietal, R. (1997). Mesuring sustainable development: Review of current practice. New York: Van Nostrand Reinhold.

Hedari, Q. (2010). [The factor influencing the participation of pastoralists in implementation of range management projects (Persian)] (PhD thesis). Gorgan: Gorgan University of Agricultural Sciences and Natural Resources

Holechek, J. L., Pieper, R. D., \& Herbel, C. H. (1989). Range management: Principles and practices. New Jersey: Prentice-Hall.

Hosseini-Nasab, M., Barani, H., Dianati, Gh. A. (2011). [The examine of relationship between ownership and operational status of pasture (with emphasis on rangelands city of Arak) (Persian)]. Iranian Journal of Range and Desert Research, 17(1) , 166-79.

Kakumba, U. (2010). Local government citizen participation and rural development: reflections on Uganda's decentralization system. International Review of Administrative Sciences, 76(1), 171-186. doi: 10.1177/0020852309359049
Kanamaru, M. (2005). Approaches for systematic planning of develop ment projects. Dehli: Kodrige.

Khalighi, M. M., Khalighi, N., \& Farahpoor, M. (2006). [Study of ecological and social sustenance of different exploitation methods (Case study: Karaj river watershed) (Persian)]. Iranian Journal of Range and Desert Research, 13(2), 82-93.

Kraaij, T., \& Milton, S. J. (2006). Vegetation changes (1995-2004) in semi-arid Karoo Shrubland, South Africa: Effects of rainfall, wild herbivores and change in land use. Journal of Arid Environments, 64(1), 174-92. doi: 10.1016/j.jaridenv.2005.04.009

Lynam, T. J. P., \& Stafford Smith, M. (2004). Monitoring in a complex world - seeking slow variables, a scaled focus, and speedier learning. African Journal of Range \& Forage Science, 21(2), 69-78. doi: $10.2989 / 10220110409485837$

Mitchell, B. (2013). Resource and environmental management. Abingdon: Routledge.

Moeineddin, H. (1993). [The process of ownership and rangeland in Iran (Persian)]. Journal of Jangal va Marta', 29, 34-42.

Moghaddam, M. R. (2007). [Range and rang management (Persian)] Tehran: University of Tehran press.

Mohamad, N. H., Kesavan, P., Razzaq, A. R. A., Hamzah, A., \& Khalifah, Z. (2013). Capacity building: Enabling learning in rural community through partnership. Procedia - Social and Behavioral Sciences, 93, 1845-9. doi: 10.1016/j.sbspro.2013.10.128

Moradi, H. R., Fazelpor, M. R., Sadeghi, H. R., Hosseini, Z. (2008) [The study of land use change on desertification using remote sensing in Ardakan area (Persian)]. Iranian Journal of Range and Desert Research, 15(1), 1-12.

Najafi, B., Shirvanian, A., \& Haghshenas, T. (2008). [Factors affecting pasture and meat production imbalance in Fars province: A case study of Koohnamak pastures in Darab (Persian)]. Journal of Science and Technology of Agriculture and Natural Resources, 12(45), 673-83.

Papely Yazdi, M. H., \& Labaf Khaniki, M. (2000). [Rangeland: Operational systems (Persian)]. Geographical Research, 15(2-1), 7-40.

Planning Department of Statistics and Information. (2012). [Statistical annals south Khorasan Province (Persian)]. Birjand: Planning Department of Statistics and Information.

Ggeitury, M., Ansari, N., Sanadgool, A., Heshmati, M. (2006). [The effective factores of destruction in Kermanshah rangelands (Persian)]. Iranian Journal of Range and Desert Research, 13(4), 314-23.

Rokneddin Eftekhari, A., \& Mahdavi, D. (2006). [Approaches to the development of rural tourism by using SWOT: Lavasan small villages (Persian)]. Human Sciences MODARES, 10(2), 1-30.

Roseland, M. (1997). Dimensions of the eco-city. Cities, 14(4), 197202. doi: 10.1016/s0264-2751(97)00003-6

Saeedi Garaghani, H. R., Heidari, G,. Barani, H., Alavi., Z. (2013) [Assessment of Problems rangeland permanent management in watershed land from exploitations view point (Case study: Damavand Summer Rangeland in Amol County) (Persian)]. Jour nal of Range and Watershed Managment, 66(2), 277-86.

Sayre, N. F. (2004). Viewpoint: The need for qualitative research to understand ranch management. Journal of Range Management, 57(6), 668-74. doi: 10.2307/4004026 
Statistical Center of Iran. (2011). [The census of population and housing in 2011(Persian)]. Tehran: Statistical Center of Iran.

Timah, E. A., Ajaga, N., Tita, D. F., Ntonga, L. M., \& Bongsiysi, I. B. (2008). Demographic pressure and natural resources conservation. Ecological Economics, 64(3), 475-83. doi: 10.1016/j. ecolecon.2007.08.024

Todaro, M. P. (1977). Economic development in the third world. Population and Development Review, 3(4), 510. doi: 10.2307/1971711

Willer, H., \& Kilcher, L. (2009). The world of organic agriculture: Statistics and emerging trend. Switzerland: International Federation of Organic Agriculture Movements Publishing. 